\title{
Epidemiology and patterns of tracheostomy practice in patients with acute respiratory distress syndrome in ICUs across 50 countries
}

Toshikazu Abe ${ }^{1,2^{*}}$, Fabiana Madotto ${ }^{3}$, Tài Pham ${ }^{4,5}$, Isao Nagata², Masatoshi Uchida², Nanako Tamiya², Kiyoyasu Kurahashi ${ }^{6}$, Giacomo Bellani ${ }^{7}$, John G. Laffey ${ }^{4,5,8}$ and for the LUNG-SAFE Investigators and the ESICM Trials Group

\begin{abstract}
Background: To better understand the epidemiology and patterns of tracheostomy practice for patients with acute respiratory distress syndrome (ARDS), we investigated the current usage of tracheostomy in patients with ARDS recruited into the Large Observational Study to Understand the Global Impact of Severe Acute Respiratory Failure (LUNG-SAFE) study.
\end{abstract}

Methods: This is a secondary analysis of LUNG-SAFE, an international, multicenter, prospective cohort study of patients receiving invasive or noninvasive ventilation in 50 countries spanning 5 continents. The study was carried out over 4 weeks consecutively in the winter of 2014, and 459 ICUs participated. We evaluated the clinical characteristics, management and outcomes of patients that received tracheostomy, in the cohort of patients that developed ARDS on day 1-2 of acute hypoxemic respiratory failure, and in a subsequent propensity-matched cohort.

Results: Of the 2377 patients with ARDS that fulfilled the inclusion criteria, 309 (13.0\%) underwent tracheostomy during their ICU stay. Patients from high-income European countries $(n=198 / 1263)$ more frequently underwent tracheostomy compared to patients from non-European high-income countries $(n=63 / 649)$ or patients from middle-income countries ( $n=48 / 465)$. Only 86/309 (27.8\%) underwent tracheostomy on or before day 7 , while the median timing of tracheostomy was $14(\mathrm{Q} 1-\mathrm{Q} 3,7-21)$ days after onset of ARDS. In the subsample matched by propensity score, ICU and hospital stay were longer in patients with tracheostomy. While patients with tracheostomy had the highest survival probability, there was no difference in 60-day or 90-day mortality in either the patient subgroup that survived for at least 5 days in ICU, or in the propensity-matched subsample.

Conclusions: Most patients that receive tracheostomy do so after the first week of critical illness. Tracheostomy may prolong patient survival but does not reduce 60-day or 90-day mortality.

Trial registration: ClinicalTrials.gov, NCT02010073. Registered on 12 December 2013.

Keywords: Tracheostomy, Acute respiratory distress syndrome (ARDS), ICU, Ventilation, Propensity-matched analysis

\footnotetext{
* Correspondence: abetoshi111@gmail.com

${ }^{1}$ Department of General Medicine, Juntendo University, 2-1-1, Hongo, Bunkyo-ku,

Tokyo 113-0033, Japan

${ }^{2}$ Department of Health Services Research, University of Tsukuba, Tsukuba,

Japan
}

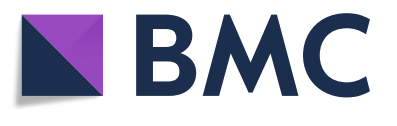

(c) The Author(s). 2018 Open Access This article is distributed under the terms of the Creative Commons Attribution 4.0 International License (http://creativecommons.org/licenses/by/4.0/), which permits unrestricted use, distribution, and reproduction in any medium, provided you give appropriate credit to the original author(s) and the source, provide a link to the Creative Commons license, and indicate if changes were made. The Creative Commons Public Domain Dedication waiver (http://creativecommons.org/publicdomain/zero/1.0/) applies to the data made available in this article, unless otherwise stated. 


\section{Background}

Tracheostomy is a widely used intervention in patients with acute respiratory failure, especially when clinicians predict a patient's need for prolonged mechanical ventilation. This well-tolerated procedure reduces the requirement for sedation, results in better patient comfort, and facilitates earlier resumption of patient autonomy $[1,2]$. On the other hand, tracheostomy carries risks of adverse events including procedure-related complications including death (albeit rare) and later cosmetic concerns [3]. The use of this procedure has increased over the last decade, in part because of the introduction of a practical bedside percutaneous tracheostomy technique.

Acute respiratory distress syndrome (ARDS) is a major cause of respiratory failure and presents significant clinical challenges. It accounts for about $10 \%$ of ICU admissions [4]. The Large observational study to understand the global impact of severe acute respiratory failure (LUNG-SAFE study) showed that this syndrome was both under-recognized and under-treated and associated with a high mortality rate [5]. In this study, tracheotomy was performed on $13 \%$ of the patients with ARDS [5]. However, few data are available on the current practice of tracheostomy in the ICU setting [6]. Studies examining tracheostomy practices have been confined to single countries [7], sometimes gathered in meta-analyses $[8,9]$. There is a lack of detailed information on global patterns of the use of tracheostomy, patient characteristics, the management of patients with tracheostomy, and the outcomes of these patients [10]. The impact on clinical practice of the TracMan clinical trial [11], which showed no benefit for early compared to later tracheostomy, remains unclear. Given these issues, the aim of our study was to investigate by secondary analysis the current patterns of tracheostomy usage in patients with ARDS requiring invasive mechanical ventilation.

\section{Methods}

\section{Design, setting, and participants}

This is a sub-study of the LUNG-SAFE study, an international, multicenter, prospective cohort study of patients receiving invasive or noninvasive ventilation. LUNG-SAFE used a convenience sample of 459 ICUs located in 50 countries, spanning 6 continents. The study was conducted over 4 weeks consecutively in each participating ICU in the winter of 2014 [5]. This study examined current use of tracheostomy in patients with ARDS requiring mechanical ventilation in ICUs. We included adult patients ( $\geq 16$ years old) fulfilling ARDS criteria (according to the Berlin definition) who received invasive mechanical ventilation on day 1 or 2 from onset of acute hypoxemic respiratory failure (Fig. 1).

\section{Data collection and analysis}

LUNG-SAFE is registered with ClinicalTrials.gov, number NCT02010073. Data were obtained from the LUNG-SAFE database, which was collected by the LUNG-SAFE investigators and the European Society of Intensive Care Medicine (ESICM) Trials Group [5]. Our study population was divided into two groups (tracheostomy and non-tracheostomy) according to whether tracheostomy was performed during the first 28 days in ICU after onset of acute hypoxemic respiratory failure. In each group, demographic factors, ARDS risk factors, patients' comorbidities, illness severity, management factors such as ventilation setting measured on the day of ARDS onset, and outcomes that occurred during the ICU and hospital stay (days of mechanical ventilation, ventilator free days (VFDs), length of stay, and 28-day, 60-day, and 90-day mortality) were analyzed. In order to reduce the impact of the immortal time bias (i.e. bias due to fact that the patient had to be alive and still in the ICU to receive a tracheostomy) for tracheostomized patients, length of ICU and hospital stay, and 28-day, 60-day and 90-day mortality were calculated from the first day on which the investigator reported that the patient was tracheostomized. The impact of geo-economic location was also examined, with 3 areas defined: (1) European countries with high income, (2) non-European rest of world high-income countries (rWORLD), and (3) middle-income countries [10]. VFDs were defined as the number of days a patient was breathing without a ventilator during the 28-day study period, which began at the time of enrollment. Patients who died during the study period were assigned 0 for the number of VFDs. Since the amount of missing values was low, as previously reported [1], no assumptions were made for missing data.

Descriptive statistics included proportions for categorical variables and mean (standard deviation) or median (interquartile range (Q1-Q3)) for continuous variables. Comparisons between groups were assessed using the chi-square or Fisher exact test for discrete variables and Student $t$ test or Wilcoxon rank-sum test for continuous variables, according to the data distribution (evaluated using the Shapiro-Wilk test). ICU and hospital mortality were evaluated at ICU or hospital discharge, or at day 90, whichever occurred first [4]. Survival analysis (Kaplan-Meier (K-M) approach) was performed to investigate the time to survival in patients with or without tracheostomy. We assumed that patients discharged alive from hospital before 90 days were alive on day 90 . The difference in K-M curves between the groups was assessed using the log-rank test. We further evaluated the outcomes in the subgroup of patients who had ICU stays of at least 5 days duration (from acute hypoxemic respiratory failure onset), excluding those who died 
within 4 days, in order to reduce the potential for immortal time bias.

\section{Propensity-score matching}

To assess the effect of tracheostomy on hospital mortality and other outcomes of interest and to reduce the potential for confounding by selection, we matched patients using the propensity-score matching approach. Logistic regression was used to estimate propensity scores able to predict the probability of undergoing tracheostomy. We included predictors that would affect the indication for tracheostomy (chosen a priori as possibly influencing the choice between tracheostomy or not): age, gender, and body mass index (BMI), region of enrollment, type of admission (medical, surgical planned or not, and trauma), comorbidities, ARDS risk factors (no risk factors, only direct risk factor, only indirect risk factor, both risk factors), use of extracorporeal memberane oxygenation (ECMO), arterial gas measures $(\mathrm{pH}$, partial arterial pressure of oxygen $\left(\mathrm{PaO}_{2}\right) /$ inspired fraction of oxygen $\left(\mathrm{F}_{\mathrm{I}} \mathrm{O}_{2}\right)$, and partial arterial pressure of carbon dioxide $\left(\mathrm{PaCO}_{2}\right)$ ) and non-respiratory sequential failure organ assessment (SOFA) score adjusted for missing values measured at date of ARDS onset. For tracheostomized patients, we used arterial blood gas and SOFA score measured on the last day before tracheostomy. Patients with similar propensity score in the two groups were matched (1:1 match without replacement), using a caliper of 0.2 standard deviation of the logit of the propensity score. We matched the data of the tracheostomized patient on one day before tracheostomy with those of a non-tracheostomized patient when they met the criteria for ARDS. We assessed the similarity of the matched groups through the standardized differences of each predictor. Statistical significance of the difference in means was evaluated by paired $t$ test or Wilcoxon signed-rank test, while for the difference in proportions we applied McNemar's test. The primary

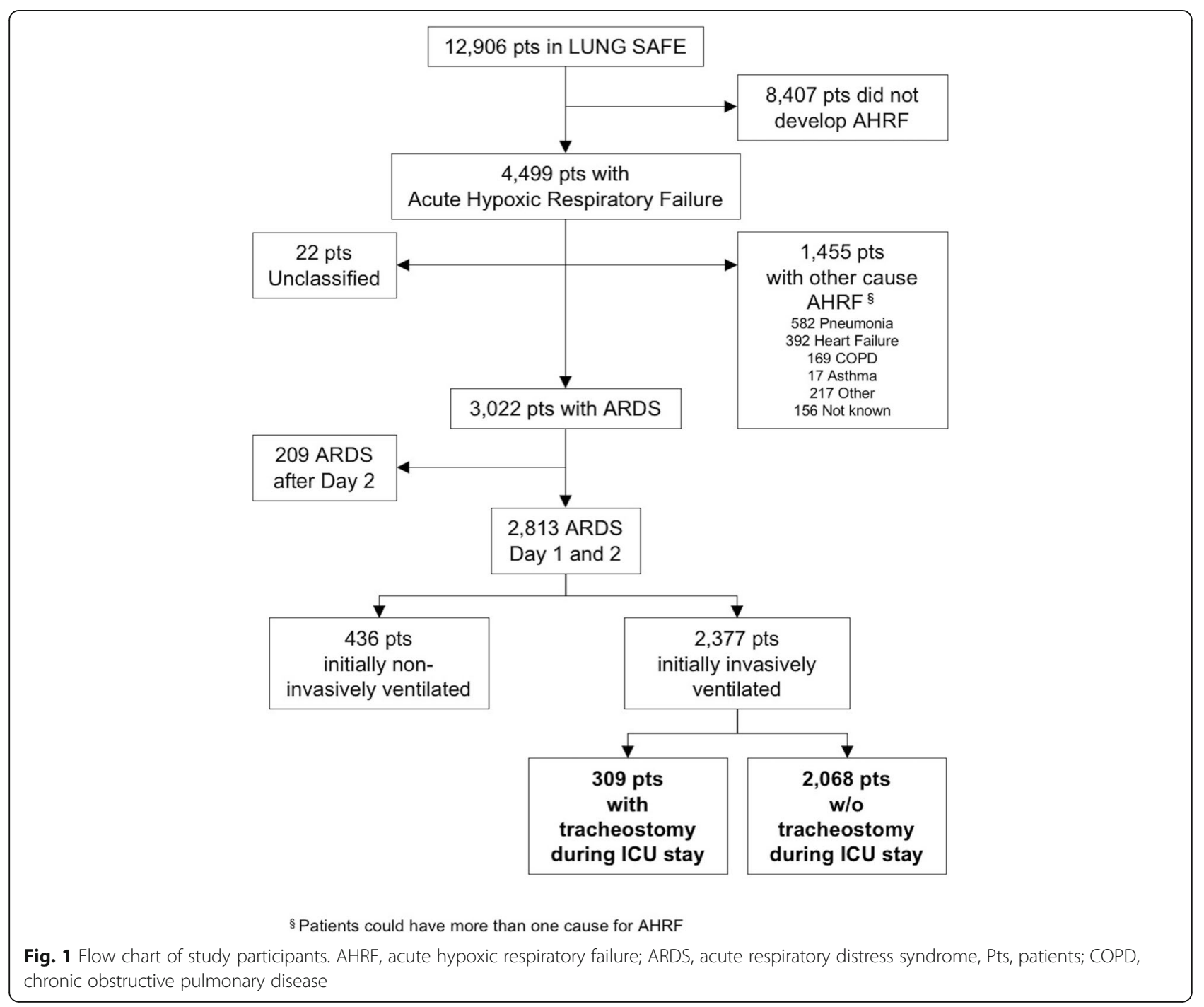


outcome was 90-day survival. The difference between the K-M survival curves in matched groups was assessed according to the test proposed by Klein and Moeschberger.

All $P$ values were two-sided, with $P$ values less than 0.05 considered as statistically significant. Statistical analyses were performed using SAS software, version 9.4 (SAS Institute, Cary, NC, USA) and R, version 3.3.3 (R Project for Statistical Computing, http://www.R-project.org).

\section{Results}

Of the 2377 participants who were diagnosed with ARDS, according to the Berlin definition, on the 1st or 2nd day following development of acute hypoxemic respiratory failure and initially invasively ventilated, 309 (13.0\%) underwent tracheostomy during their ICU stay (Fig. 1).

Patient demographics, including age, gender, and BMI did not differ between patients with or without tracheostomy (Table 1). There were significant variations with geo-economic region associated with the frequency of tracheostomy $(P=0.0002)$. High-income European areas had a greater frequency of tracheostomy than other areas. However, there was no significant difference in the frequency of undergoing tracheostomy between rWORLD countries and middle-income countries $(P=0.7353)$. Severity of ARDS at day 1 was also similar between the two groups (Table 1). Patients undergoing tracheostomy were more likely to have undergone elective surgery (Table 1), to have come from other hospital ICUs, have a lower frequency of chronic liver failure, and a higher frequency of pneumonia compared to patients that did not receive a tracheostomy (Additional file 1: Table S1). A large proportion of patients who received a tracheostomy received mechanical ventilation with spontaneous ventilator modes. Additional file 1 shows this in more detail. More patients who were on ECMO received tracheostomy compared to patients who were not on ECMO (Table 1).

The median timing of tracheostomy was $14(\mathrm{Q} 1-\mathrm{Q} 3$, 7-21) days after onset of ARDS. Only $27.8 \%$ patients received tracheostomy within 7 days (Fig. 2), whereas $74.8 \%$ received it within 14 days. There was no difference in unadjusted outcome between patients receiving early versus late tracheostomy (Additional file 2: Table S2). Additional file 2 shows this in more detail.

The duration of mechanical ventilation in patients that received tracheostomy was significantly longer than that in those that did not (median (Q1-Q3) 21.5 (13-33) days vs $7(4-13)$ days, $P<0.0001)$ (Table 2). Moreover, VFDs in the tracheostomy group was significantly shorter than in the non-tracheostomy group (median (Q1-Q3) $0(0-13)$ days vs $15(0-23)$ days, $P<0.0001)$. The length of ICU and hospital stay was also longer in patients that received tracheostomy (11 (5-23) days vs 8
(4-15) days, $P<0.0001$ and $24(9-44)$ days vs $14(7-27)$ days, $P<0.0001$, respectively).

The 28-day crude mortality in tracheostomized patients (23.4\%) was lower than that in non-tracheostomized patients (38.1\%). The 60-day and 90-day crude mortality in tracheostomized patients were both lower than that in non-tracheostomized patients $(29.5 \%$ vs $41.1 \%, P=0.0001$ and $30.8 \%$ vs $41.8 \%, P=0.0003$, respectively). Survival analyses showed that, at any instance during the first 90 days after enrollment, tracheostomized patients were less likely to die than those in the non-tracheostomy group (30 days, $P<0.0001 ; 60$ days $P<0.0001 ; 90$ days, $\mathrm{P}=0.0001$; Table 2 and Fig. 3).

To reduce the impact of survivor bias, we analyzed the subgroup of patients who had been in the ICU for at least 5 days $(n=1670)$. Of these patients, $17.4 \%$ were tracheostomized (290 patients). Again, we found that the duration of mechanical ventilation in the tracheostomy group was significantly longer than that in the non-tracheostomy group (median (Q1-Q3) 22 (14-34) days versus $10(7-16)$ days, $P<0.0001)$. Also, the length of hospital stay in the tracheostomy group was significantly longer than that in the non-tracheostomy group (25.5 (11-45) vs $20(12-34)$ days, $P=0.0375)$, but the length of ICU stay was similar (12 (6-24) vs $12(8-20)$ days, $P=0.2735)$. While 28 -day mortality was significantly lower in patients that underwent tracheostomy ( $22.4 \%$ vs $30.3 \%)$, there was no significant difference between groups in 60 -day $(29.0 \%$ vs $34.6 \%, P=0.06)$ or 90 -day $(30.3 \%$ vs $35.6 \%, P=0.09)$ mortality.

In the propensity-matched analysis, 534 patients with and without tracheostomy were matched ( $n=267$ per group). Table 3 lists the baseline characteristics of propensity-matched patients. There was no significant difference in the chosen covariates between matched tracheostomized patients and non-tracheostomized patients (all standardized differences $<0.1$ ). The histograms of the logit of propensity scores showed the good quality of the matching procedure (Fig. 4). The duration of mechanical ventilation in the tracheostomy group was significantly longer than that in the non-tracheostomy group (median (Q1-Q3) 22 (12-33.5) days vs Q1-Q3 (4-12) days, $P<$ $0.0001)$. The length of ICU and hospital stay in the tracheostomy group was significantly longer than that in the non-tracheostomy group (11 (5-24) vs Q1-Q3 (5-14) days, $P<0.0001$ and $24(9-43)$ vs $17(10-31)$ days, $P=$ 0.0190 , respectively). Survival analysis showed that patients receiving tracheostomy had higher survival probability during the follow-up time compared to those without it (Klein and Moeschberger test, $P=0.0379$ ) (Fig. 5). While the 28-day mortality was lower in the tracheostomy group as compared with non-tracheostomy group (22.9\% vs $31.8 \%, P=0.02)$ (Table 4 ), the 60 -day (29.3\% vs $36.3 \%, P=0.08)$ or 90 -day $(30.5 \%$ vs $38.2 \%, P$ 
Table 1 Baseline characteristics in patients with tracheostomy and patients with no tracheostomy. $(n=2377)$

\begin{tabular}{|c|c|c|c|}
\hline & Tracheostomy $(n=309)$ & No tracheostomy $(n=2068)$ & $P$ value \\
\hline & $\begin{array}{l}\text { Number (\%) or median } \\
\text { (Q1-Q3) }\end{array}$ & $\begin{array}{l}\text { Number (\%) or median } \\
\text { (Q1-Q3) }\end{array}$ & \\
\hline Age (years) & $63(49-72)$ & $63(50-74)$ & 0.1443 \\
\hline Sex (male) & $200(64.7)$ & $1272(61.5)$ & 0.2775 \\
\hline $\mathrm{BMI}\left(\mathrm{kg} / \mathrm{m}^{2}\right)$ & $27.1(23.1-30.8)$ & $26.0(22.9-30.4)$ & 0.1410 \\
\hline Geo-economic area & & & 0.0002 \\
\hline European countries with high income & 198/1263 (15.7) & 1065/1263 (84.3) & \\
\hline Non-European countries (rest of world) with high income & $63 / 649(9.7)$ & $586 / 649(90.3)$ & \\
\hline Countries with middle income & $48 / 465(10.3)$ & $417 / 465(89.7)$ & \\
\hline Severity of ARDS at day 1 & & & 0.9271 \\
\hline Mild & $95(30.7)$ & $619(29.9)$ & \\
\hline Moderate & $144(46.6)$ & $962(46.5)$ & \\
\hline Severe & $70(22.7)$ & $487(23.6)$ & \\
\hline Type of admission & & & 0.0194 \\
\hline Medical & $211(68.3)$ & $1554(75.2)$ & \\
\hline Surgical & $20(6.5)$ & $123(6.0)$ & \\
\hline Postoperative (elective) & $56(18.1)$ & $310(15.0)$ & \\
\hline Trauma & $22(7.1)$ & $81(4.0)$ & \\
\hline \multicolumn{4}{|l|}{ Cause of AHRF } \\
\hline Pneumonia & $213(68.9)$ & 1295 (62.6) & 0.0317 \\
\hline Cardiac failure & $43(12.9)$ & $311(15.0)$ & 0.6051 \\
\hline Asthma & $4(1.3)$ & $29(1.4)$ & 1.0000 \\
\hline ARDS (i.e. clinician recognized) & $103(33.3)$ & $684(33.1)$ & 0.9284 \\
\hline COPD & $29(9.4)$ & 205 (9.9) & 0.7714 \\
\hline Unknown & $15(4.9)$ & $117(5.7)$ & 0.5652 \\
\hline Others & $54(17.5)$ & $418(20.2)$ & 0.2606 \\
\hline ARDS risk factor & & & 0.1675 \\
\hline No risk factor & $19(6.1)$ & $157(7.6)$ & \\
\hline Only indirect risk factors & $53(17.1)$ & $429(20.7)$ & \\
\hline Only direct risk factors & $194(62.8)$ & $1160(56.1)$ & \\
\hline Both risk factor types & $43(13.9)$ & $322(15.6)$ & \\
\hline \multicolumn{4}{|l|}{ Illness severity at ARDS onset } \\
\hline $\mathrm{pH}$ & $7.37(7.29-7.43)$ & $7.34(7.26-7.41)$ & $<.0001$ \\
\hline $\mathrm{P} / \mathrm{F}$ ratio $(\mathrm{mmHg})$ & $156(110-213)$ & $154(103-215)$ & 0.6845 \\
\hline $\mathrm{PaCO} 2(\mathrm{mmHg})$ & $42(36-50)$ & $43(37-51)$ & 0.2751 \\
\hline Non-respiratory SOFA score (adjusted for missing values) (ARDS onset) & $6(4-9)$ & $7(4-10)$ & 0.0010 \\
\hline Non-respiratory SOFA score (adjusted for missing values) at day 2 & $6(4-9)$ & $6(4-10)$ & 0.1333 \\
\hline Difference in non-respiratory SOFA score (day2-day1) (adjusted for missing values) & $0(-2-2)$ & $0(-2-2)$ & 0.9598 \\
\hline \multicolumn{4}{|l|}{ Mechanical ventilation settings at ARDS onset } \\
\hline Respiratory rate (set) (breaths/min) & $18(15-22)$ & $16(14-20)$ & 0.0016 \\
\hline Respiratory rate (total) (breaths/min) & $20(15-25)$ & $20(16-24)$ & 0.2406 \\
\hline Tidal volume (ml) & $488(400-550)$ & $457(400-516)$ & 0.0105 \\
\hline Tidal volume/IBW (ml/kg) & $7.55(6.34-8.96)$ & $7.35(6.39-8.48)$ & 0.4519 \\
\hline PEEP (cmH2O) & $8(5-10)$ & $8(5-10)$ & 0.0254 \\
\hline
\end{tabular}


Table 1 Baseline characteristics in patients with tracheostomy and patients with no tracheostomy. $(n=2377)$ (Continued)

\begin{tabular}{|c|c|c|c|}
\hline & \multirow{2}{*}{$\begin{array}{l}\text { Tracheostomy }(n=309) \\
\text { Number }(\%) \text { or median } \\
\text { (Q1-Q3) }\end{array}$} & \multirow{2}{*}{$\begin{array}{l}\text { No tracheostomy }(n=2068) \\
\text { Number }(\%) \text { or median } \\
\text { (Q1-Q3) }\end{array}$} & \multirow[t]{2}{*}{$P$ value } \\
\hline & & & \\
\hline Plateau pressure $(\mathrm{cmH} 2 \mathrm{O})(n=79, n=663)$ & $24(20-27)$ & $23(18-28)$ & 0.4957 \\
\hline Peak inspiratory pressure $(\mathrm{cmH} 2 \mathrm{O})$ & $27(21-32)$ & $26(22-32)$ & 0.6444 \\
\hline Mean airway pressure $(\mathrm{cmH} 2 \mathrm{O})$ & $14(11-18)$ & $14(11-18)$ & 0.4912 \\
\hline \multicolumn{4}{|l|}{ Use of adjuncts } \\
\hline ECMO use & $20(6.5)$ & $35(1.7)$ & $<.0001$ \\
\hline High-dose corticosteroids & $36(11.7)$ & $225(10.9)$ & 0.6862 \\
\hline Continuous sedation & $234(75.7)$ & $1567(75.8)$ & 0.9861 \\
\hline Continuous neuromuscular blocking agents & $34(11.0)$ & $286(13.8)$ & 0.1745 \\
\hline Renal replacement therapy & $35(11.3)$ & $169(8.2)$ & 0.0648 \\
\hline Inhaled vasodilators & $19(6.2)$ & $84(4.1)$ & 0.0928 \\
\hline Neutrophil elastase therapy & $3(1.0)$ & $10(0.5)$ & 0.2334 \\
\hline Vasopressor used & $163(52.8)$ & $1212(58.6)$ & 0.0518 \\
\hline
\end{tabular}

$B M I$ body mass index, ICU intensive care unit, $E R$ emergency room, COPD chronic obstructive pulmonary disease, NYHA New York heart association, AHRF acute hypoxemic respiratory failure, $A R D S$ acute respiratory distress syndrome, TRAL/ transfusion-related acute lung injury, $A / C$ assist control, $P C$ pressure control, BIPAP bilevel positive airway pressure, APRV airway pressure release ventilation, SIMV synchronized intermittent mandatory ventilation, PRVC pressure-regulated volume control, PSV pressure support ventilation, HFO high-frequency oscillation, CPAP continuous positive airway pressure, IBW ideal body weight, PEEP positive end-expiratory pressure, ECMO extracorporeal membrane oxygenation, SOFA sequential organ failure assessment, $\mathrm{PaCO} 2$ partial arterial pressure of carbone dioxide

Missing data: $\mathrm{BMI}=127 ; \mathrm{Ph}=25, \mathrm{PaCO} 2=25$, respiratory rate $(\mathrm{set})=250$, respiratory rate (total) $=10$, tidal volume $=24$, tidal volume/lBW $=122$, peak inspiratory pressure $=89$, mean airway pressure $=687$, non-respiratory SOFA score (adjusted for missing values) $=22$, non-respiratory SOFA score (adjusted for missing values) at day $2=379$, difference in non-respiratory SOFA score (day2-day1) (adjusted for missing values) $=384$

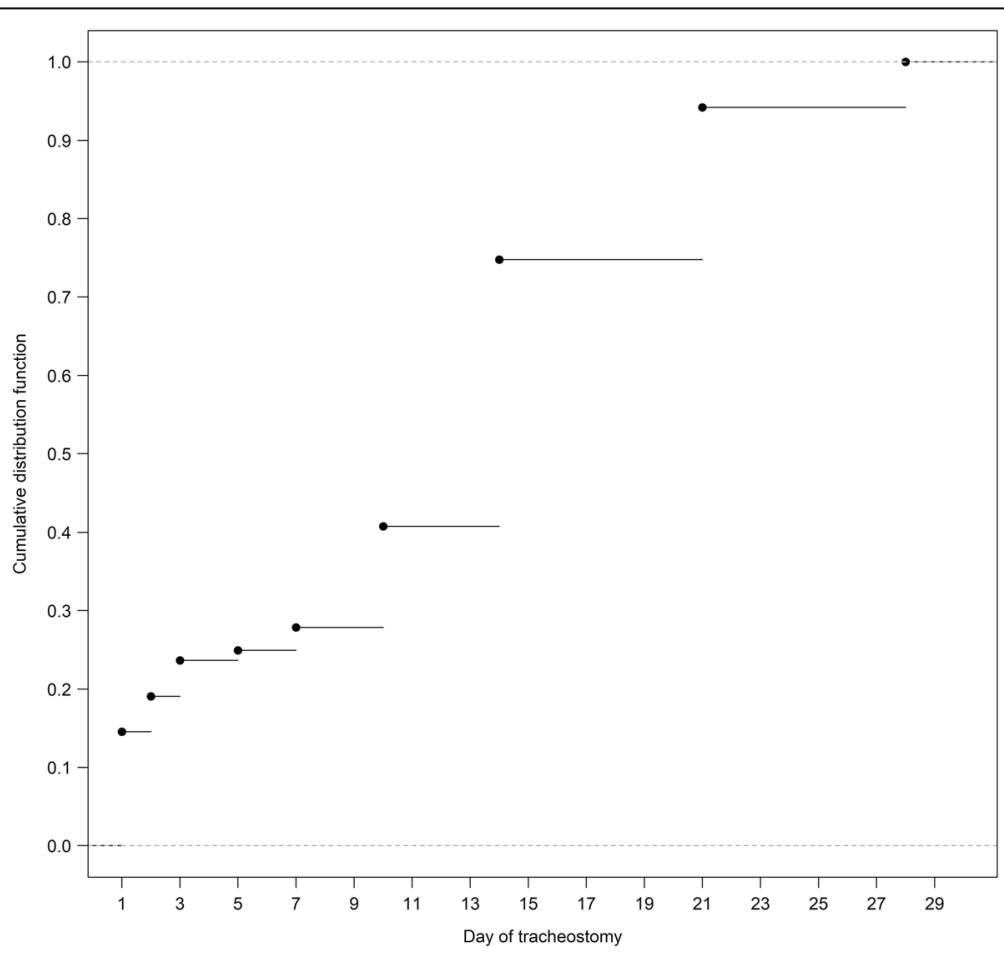

Fig. 2 Distribution of time to tracheostomy $(n=309)$ 
Table 2 Outcomes in patients with tracheostomy and patients with no tracheostomy $(n=2377)$

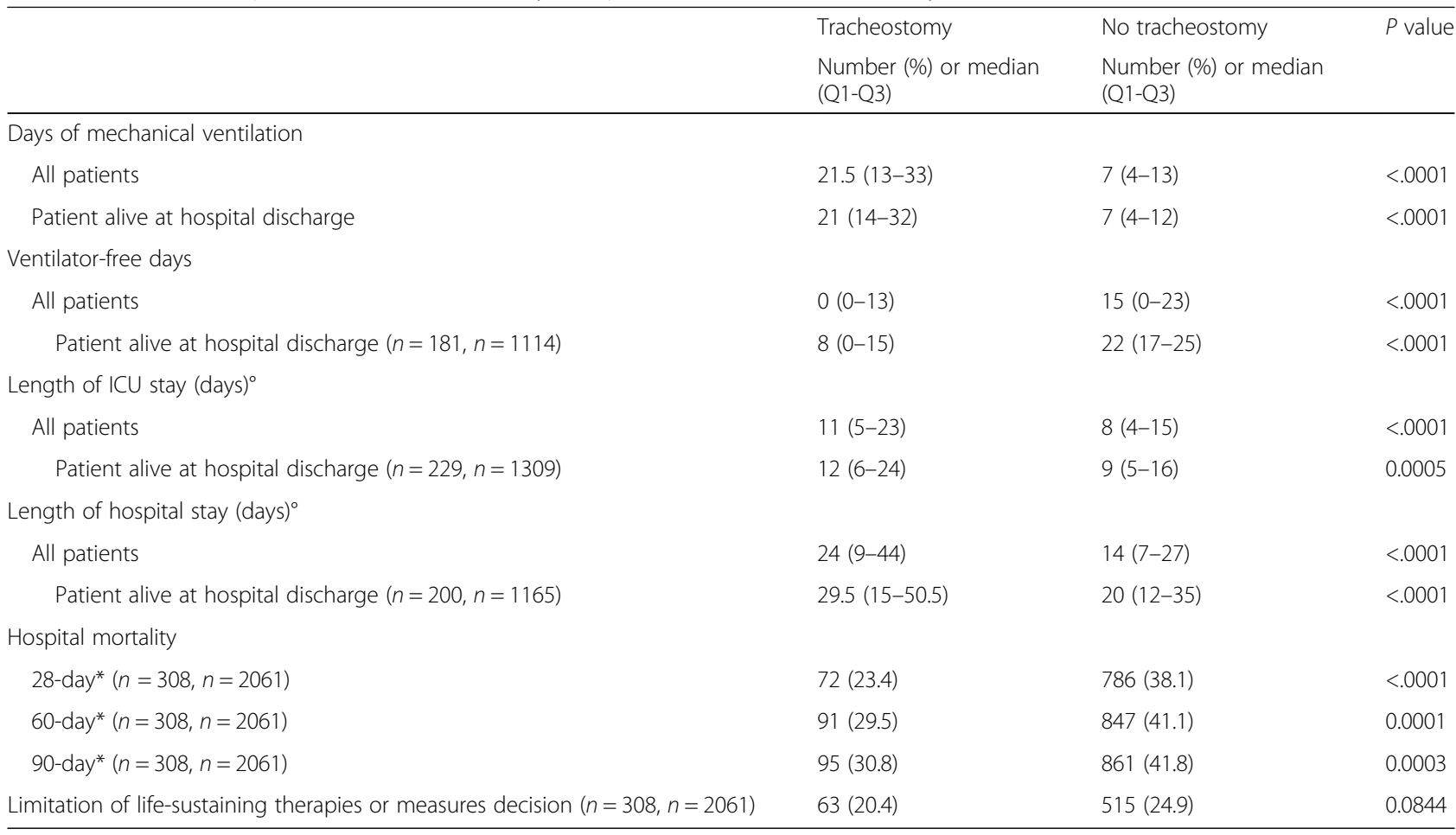

SD standard deviation, ICU intensive care unit, Q1-Q3 25th-75th percentile

"For tracheostomized patients, length of stay was calculated from the "approximate" date of tracheostomy

*Mortality was evaluated according to the vital status at 28/60/90 days from acute respiratory distress syndreom onset or from the "nearest recorded" date of tracheostomy in non tracheostomized and tracheostomized patients, respectively. If the patient was discharged alive before $28 / 60 / 90$ days, we considered the patient as alive

$=0.055)$ mortality ratio was not significantly different between tracheostomized and non-tracheostomized patients.

\section{Discussion}

Tracheostomy was performed in $13 \%$ of patients with ARDS that were recruited to the LUNG SAFE international, multicenter, prospective cohort study from 459 ICUs across 50 countries, predominantly (75\%) after the first week of their critical illness. Patients with tracheostomy remained longer on mechanical ventilation, and stayed longer in the ICU and in the hospital than non-tracheostomized patients. While duration of survival was increased in patients that received a tracheostomy, there was no significant increase in 60-day or 90-day survival compared to patients that did not receive a tracheostomy.

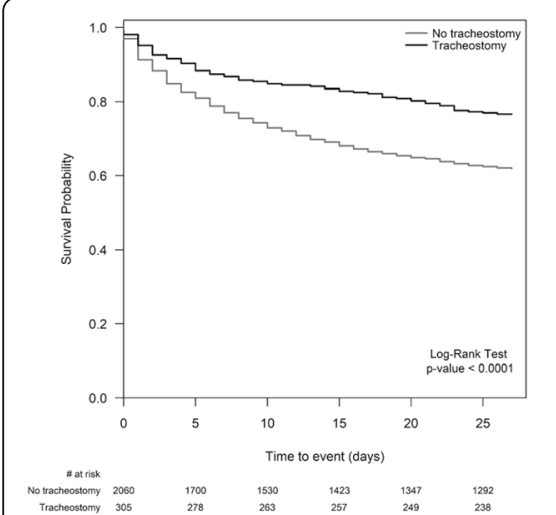

a

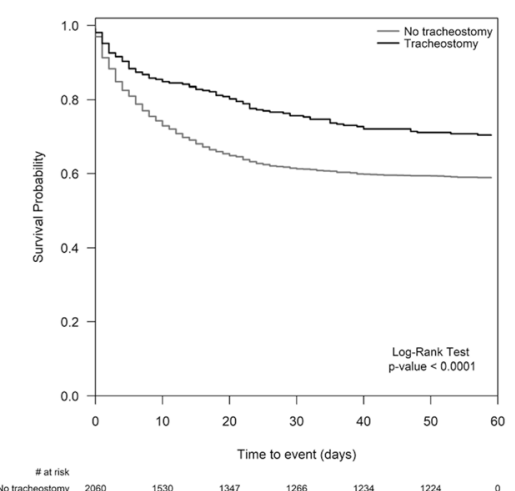

b

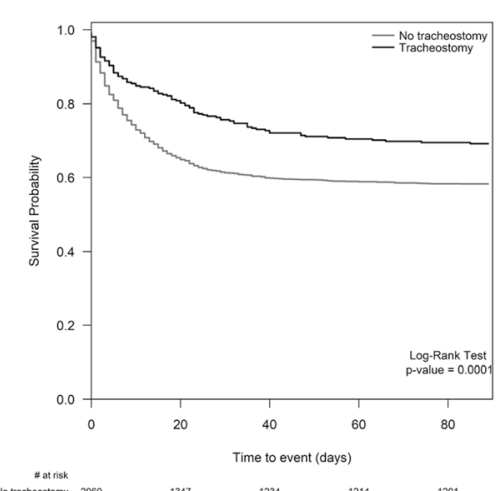

C

Fig. 31 Survival probability during the first 28 days. 2 Survival probability during the first 60 days. 3 Survival probability during the first 90 days 
Table 3 Description of each covariate used for the propensity-score matching in the matched sample $(n=534)$

\begin{tabular}{|c|c|c|c|}
\hline & Tracheostomy & No tracheostomy & Standardized \\
\hline & Number (\%) or mean \pm sd & Number (\%) or mean \pm sd & \\
\hline Number & 267 & 267 & \\
\hline Age & $58.4 \pm 16.6$ & $58.9 \pm 17.9$ & 0.03 \\
\hline Sex (male) & $171(64.0)$ & $171(64.0)$ & 0.00 \\
\hline BMI & $27.9 \pm 7.8$ & $27.9 \pm 15.0$ & 0.00 \\
\hline Geographic area & & & \\
\hline European countries with high income & $174(64.2)$ & $172(64.4)$ & 0.02 \\
\hline Non-European countries with high income & 49 (18.4) & $48(18.0)$ & 0.01 \\
\hline Countries with middle income & $44(16.5)$ & $47(17.6)$ & 0.03 \\
\hline Type of admission & & & \\
\hline Medical & $178(66.7)$ & $183(68.5)$ & 0.04 \\
\hline Surgical & $52(19.5)$ & $48(18.0)$ & 0.04 \\
\hline Elective & $19(7.1)$ & $21(7.9)$ & 0.03 \\
\hline Trauma & $18(6.7)$ & $15(5.6)$ & 0.05 \\
\hline Comorbidities & & & \\
\hline COPD or home ventilation & $60(22.5)$ & $65(24.3)$ & 0.04 \\
\hline Diabetes mellitus & $64(23.9)$ & $64(23.9)$ & 0.00 \\
\hline Chronic renal failure & $27(10.1)$ & $23(8.6)$ & 0.05 \\
\hline Immunosuppression or active or hematologic neoplasm & $66(24.7)$ & $62(23.3)$ & 0.04 \\
\hline Heart failure (NYHA classes III-IV) & $19(7.1)$ & $22(8.2)$ & 0.04 \\
\hline Chronic liver failure (Child-Pugh Class C) & $2(0.7)$ & $2(0.7)$ & 0.00 \\
\hline Cause of AHRF - pneumonia & $186(69.7)$ & $195(73.0)$ & 0.07 \\
\hline ARDS risk factor & & & \\
\hline No risk factor & $17(6.4)$ & $17(6.4)$ & 0.00 \\
\hline Only indirect risks factor & $45(16.9)$ & $39(14.6)$ & 0.06 \\
\hline Only direct risk factors & $168(62.9)$ & $173(65.0)$ & 0.04 \\
\hline Both risk factors & $37(13.9)$ & $38(14.2)$ & 0.01 \\
\hline ECMO use & $19(7.1)$ & $16(6.0)$ & 0.05 \\
\hline Arterial gas & & & \\
\hline $\mathrm{pH}$ & $7.4 \pm 0.1$ & $7.4 \pm 0.1$ & 0.07 \\
\hline $\mathrm{P} / \mathrm{F}$ ratio $(\mathrm{mmHg})$ & $204.1 \pm 86.5$ & $199.1 \pm 63.7$ & 0.07 \\
\hline $\mathrm{PaCO} 2(\mathrm{mmHg})$ & $44.4 \pm 13.9$ & $44.2 \pm 14.1$ & 0.01 \\
\hline Non-respiratory SOFA score adjusted for missing values, & $5.1 \pm 3.4$ & $5.1 \pm 3.6$ & 0.00 \\
\hline
\end{tabular}

\section{Use of and timing of tracheostomy}

The rate of tracheostomy in our cohort, 13\%, is higher than that reported from a nationwide population-based study from the USA, in which $9.1 \%$ of all mechanically ventilated patients underwent tracheostomy [7]. The higher rate in our cohort could be explained by the inclusion of more patients with a severe form of respiratory failure, namely ARDS. Whether it should be performed earlier versus later is controversial [12]. While some studies reported that early tracheostomy may be related to better outcomes [3, 7], a recent large-scale randomized trial, TracMan, and a subsequent meta-analysis did not confirm these findings $[11,13]$. The TracMan study demonstrated that early tracheostomy (within 4 or 5 days of critical care admission) did not improve mortality.

In our study, the median time to tracheostomy was 14 days, similar to that reported in other recent studies $[7,14]$. Only a quarter of tracheostomies were performed on or before day 7 . Of the $15 \%$ of patients who received tracheostomy on day 1 , a substantial proportion may have had an indication for a surgical airway (e.g. for upper airway obstruction). Excluding these patients would even strengthen the trend toward later tracheostomy. These findings on tracheostomy timing represent 


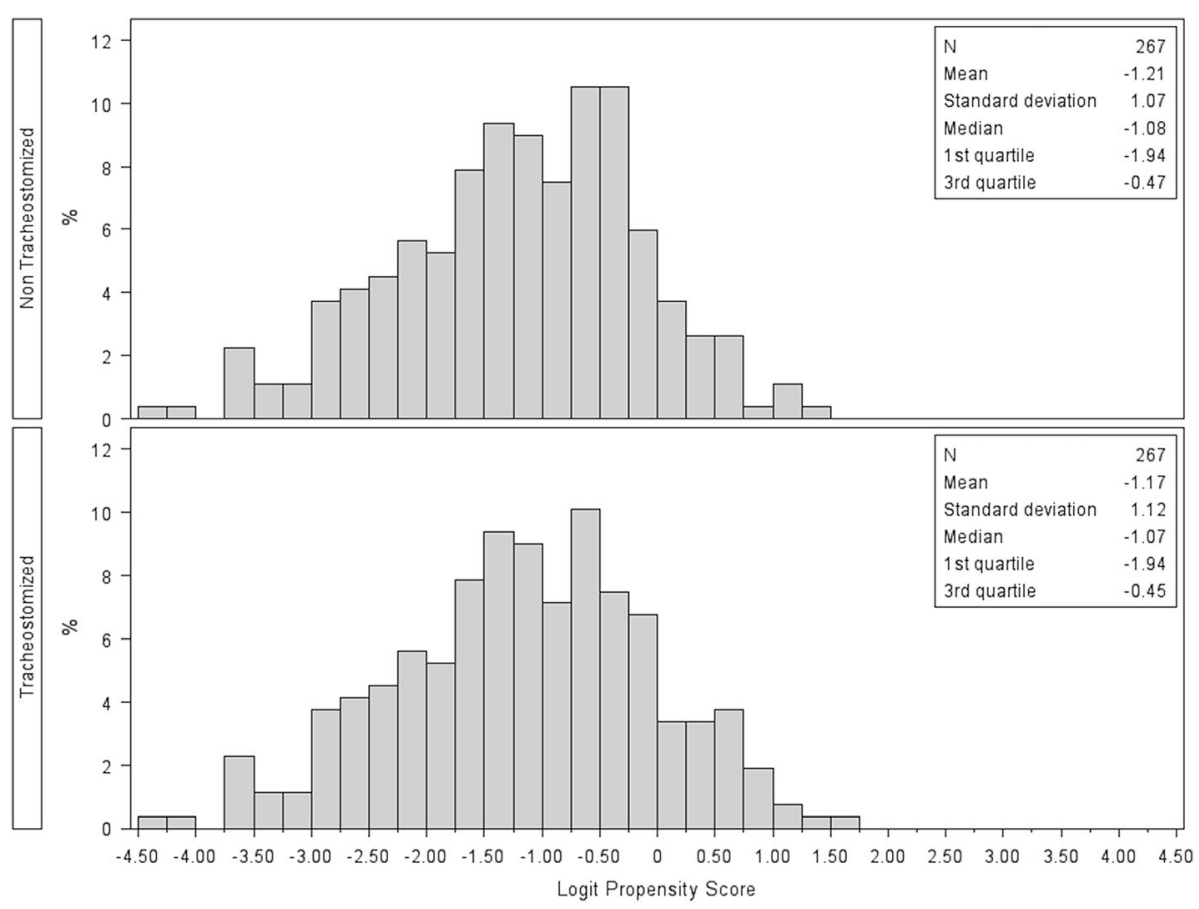

Fig. 4 Distribution of the logit of propensity scores in patients with tracheostomy $(n=267)$ and without tracheostomy $(n=267)$ in the matched sample

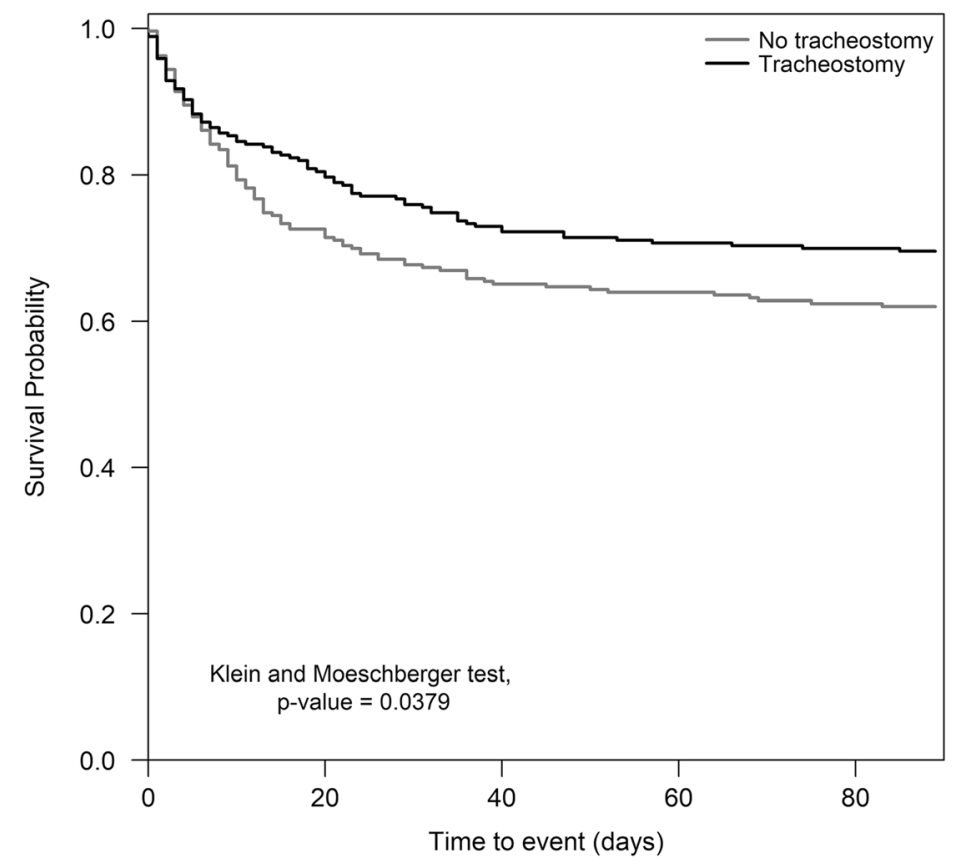

\# at risk

No tracheostomy 266

Tracheostomy 264
193

214
173

194
170

188
166

186

Fig. 5 Survival probability during the hospital stay in the matched sample $(n=534)$. Kaplan Meier's approach, assuming as censored, those patients discharged and alive before day 90 
Table 4 Description of outcomes in the propensity-matched sample $(n=534)$

\begin{tabular}{|c|c|c|c|}
\hline & Tracheostomy $(n=267)$ & No tracheostomy $(n=267)$ & $P$ value \\
\hline & Number (\%) or median (Q1-Q3) & \multicolumn{2}{|l|}{ Number (\%) or median (Q1-Q3) } \\
\hline \multicolumn{4}{|l|}{ Days of mechanical ventilation } \\
\hline All patients & $22[13-33.5]$ & $8[4-12]$ & $<.0001$ \\
\hline Patient alive at hospital discharge & 22 [13.5-33] & $6[3-11]$ & $<.0001$ \\
\hline \multicolumn{4}{|l|}{ Ventilator-free days } \\
\hline All patients & $0[0-11]$ & $18[0-25]$ & $<.0001$ \\
\hline Patient alive at hospital discharge & $7[0-15.5]$ & 23 [18-26] & $<.0001$ \\
\hline \multicolumn{4}{|l|}{ Length of ICU stay (days) ${ }^{\circ}$} \\
\hline All patients & $11[5-24]$ & $8[5-14]$ & $<.0001$ \\
\hline Patient alive at hospital discharge & $12[6-25]$ & $8[5-14]$ & 0.0002 \\
\hline \multicolumn{4}{|l|}{ Length of hospital stay (days) ${ }^{\circ}$} \\
\hline All patients & $24[9-43]$ & $17[10-31]$ & 0.0190 \\
\hline Patient alive at hospital discharge & $31[15.5-50.5]$ & 23 [13-38] & 0.0325 \\
\hline \multicolumn{4}{|l|}{ Hospital mortality } \\
\hline 28-day* & $61(22.9)$ & $85(31.8)$ & 0.0197 \\
\hline 60-day* & $78(29.3)$ & $97(36.3)$ & 0.0814 \\
\hline 90-day* & $81(30.5)$ & $102(38.2)$ & 0.0549 \\
\hline Limitation of life-sustaining therapies or measures decision & $53(19.9)$ & $59(22.1)$ & 0.5900 \\
\hline
\end{tabular}

a significant practice change, likely due to the findings of the TracMan study [11].

\section{Indications for tracheostomy}

Medical indications for tracheostomy include the need for prolonged mechanical ventilation, need for airway access for secretion removal, and improvement of patient comfort [15]. A common reason for tracheostomy is the (clinician-predicted) likelihood that the patient will require prolonged mechanical ventilation. Of interest, the TracMan study demonstrated the difficulty for clinicians in predicting which patients will require prolonged ventilation support in the early phases of critical illness, given that many of their patients randomized to later tracheostomy did not receive one. In the present study, patients that received tracheostomy had fewer ventilator-free days, and required longer ICU and hospital stays. This is not to suggest that tracheotomy delayed weaning from ventilation, but is more likely a reflection of the fact that the patients that received tracheostomy were appropriately selected as being a group that would require prolonged ventilatory support.

There was considerable variation in the use of tracheostomy by geo-economic region, suggesting there are important regional and/or socio-economic differences in clinician use of tracheostomy in patients with ARDS. We used the 2016 World Bank countries socio-economic classification, which includes data on gross national income per person, to define three major geo-economic groupings as in a previous report [10]. In high-income Europe countries, more patients underwent tracheostomy than in the other regions (non-European countries (rest of world) with high income or countries with middle income). Our findings [7] indicate that the likelihood of a patient receiving a tracheostomy appears to be influenced by factors other than those that are related to their clinical status, such as local medical practices and expertise and costs relating to the procedure and equipment.

Of interest, our study did not replicate the findings of a US study, which showed a difference in indication by patient characteristics such as gender and race/ethnicity [7]. Because our study includes data from ICUs of numerous countries and not just the USA, it might represent a more generalizable picture of worldwide patterns in the use of tracheostomy.

\section{Patient outcomes}

Aside from emergency situations, tracheostomy is usually performed in patients who are clinically relatively stable, but likely to need prolonged ventilation. This fact means that direct comparison of patients that received a tracheostomy to those that did not may be confounded by two important sources of bias, namely bias by 
indication (i.e. tracheostomy is more likely to be performed in "stable" patients) and immortal time bias (patients that die early are less likely to receive a tracheostomy). To address the latter issue, in our direct comparison of patients that received tracheostomy to those that did not, we calculated survival duration using the day of insertion of tracheostomy as "day 0". Despite this "correction", our data demonstrated significantly higher 28-day, 60-day and 90-day survival in patients that received tracheostomy.

Our subsequent analyses were designed to understand, and further minimize the potential for both types of bias. First, we stratified patients into subgroups to differentiate those who were in the ICU for at least 5 days, to reduce the impact of early death on outcomes. In this analysis, while 28-day mortality remained significantly lower in patients with tracheostomy, the trend to better 60-day and 90-day survival was not significant. These latter findings are confirmed in a propensity-matched analyses; patients undergoing tracheostomy had better 28-day, but not 60 -day or 90-day survival. This is an important finding, as it suggests that while tracheostomy prolongs short-term survival, it may not improve longer-term outcomes.

Our finding is supported by a recent systematic review and meta-analysis that suggested there was no significant difference between early and late or no tracheostomy for length of hospital stay and long-term outcomes [8], although it was not a direct comparison between patients that received a tracheostomy and those that did not. Interestingly, another population-based US study reported conflicting results [7], in that their patients with tracheostomy had shorter lengths of stay. However, the authors raised the possibility that this finding could be due to patients being discharged to long-term care facilities because of pressures to reduce length of hospital stay. They considered that the place of death could have merely shifted from hospitals to long-term care facilities [7]. This finding underlines the need for studies that seek to determine the effect of tracheostomy on outcome to examine longer-terms outcomes, including follow up of patients post hospital discharge.

\section{Limitations}

Several limitations of this study should be acknowledged. First, our study was an observational study and as such, we cannot make causal inferences. Second, the study period was relatively short and confined to the winter season, which might have led to sampling bias. However, while winter is the epidemic season of respiratory diseases such as influenza [16], the nature of the pathophysiology of ARDS does not have a significant seasonal variation. For example, seasonal variability of ARDS prevalence was modest in the recently published APRONET study [17]. A third limitation is that the group of patients who received early tracheostomy might have included patients who did not need tracheostomy. However, early tracheostomy was performed relatively infrequently in this study compared to previous studies [11]. Fourth, despite our efforts to address bias as discussed previously, the potential remains for bias by indication, and for immortal time bias to affect our results. Additional analyses, including confining the analyses to patients that were alive and in the ICU at 1 week, did not change the findings, confirming the robustness of the current findings. Although differences in goals of care may influence the tracheostomy decision, we did not find any difference in regard to end-of-life decision-making between the groups in our propensitymatched analysis, suggesting that this did not have an influence. Fifth, we did not have data on the methods of tracheostomy insertion, airway management methods, tracheostomy-related complications, and whether any deaths resulted from the tracheostomy itself is a limitation. Sixth, to control immoral bias, we chose the a cutoff point of early tracheostomy was day 4 from just TrachMan study [11]. As Fig. 2 demonstrates, moving the cutoff beyond day 5 has a limited effect: only two patients would be shifted if we changed the day of tracheostomy from day 5 to day 7. Only five patients would be shifted even if we changed the day of tracheostomy form day 5 to day 10 . Finally, a longer follow-up period (180 days or more) might be beneficial in helping understand the long-term outcomes in patients on prolonged mechanical ventilation.

\section{Conclusions}

In this international, multicenter, prospective cohort study, tracheostomy was performed in $13 \%$ of patients with ARDS, and was performed predominantly (in 75\%) after the first week of their critical illness. Patients with tracheostomy remained longer on mechanical ventilation, and stayed longer in the ICU, and in the hospital than non-tracheostomized patients. While duration of survival was increased in patients that received a tracheostomy, there was no significant increase in 60-day or 90-day survival, suggesting that tracheostomy may delay death but does not impact longer term survival.

\section{Key messages}

- Tracheostomy was performed in $13 \%$ of patients with ARDS, and was performed predominantly (in 75\%) after the first week of their critical illness.

- Patients with tracheostomy remained longer on mechanical ventilation, and stayed longer in the ICU, and in the hospital than non-tracheostomized patients.

- While duration of survival was increased in patients that received a tracheostomy, there was no significant increase in 60-day or 90-day survival.

- Tracheostomy might delay - rather than prevent death in some patients with ARDS. 


\section{Additional files}

Additional file 1: Table S1. Additional baseline characteristics in patients with tracheostomy and no tracheostomy ( $n=2377)$. BMI, body mass index; ICU, intensive care unit; ER, emergency room; COPD, chronic obstructive pulmonary disease; NYHA, New York heart association; AHRF, Acute hypoxemic respiratory failure; ARDS, acute respiratory distress syndrome; TRALI, transfusion-related acute lung injury; A/C, assist control; $\mathrm{PC}$, pressure control; BIPAP, bilevel positive airway pressure APRV, airway pressure release ventilation; SIMV, synchronized intermittent mandatory ventilation, PRVC, pressure-regulated volume control; PSV, pressure support ventilation; HFO, high-frequency oscillation; CPAP, continuous positive airway pressure IBW, ideal body weight; PEEP, positive end-expiratory pressure; ECMO, extracorporeal membrane oxygenation; SOFA, sequential organ failure assessment. Missing data: source of admission to ICU =1, Chest x-ray/CT scan number $=1$. (DOCX $27 \mathrm{~kb})$

Additional file 2: Table S2 compares outcomes between early (within 7 days of ICU admission) and late (8 days and later) thoracotomy $(n=280)$. SD, standard deviation; ICU, intensive care unit; Q1-Q3; 25\%-75\% interquartile. Missing data: days of mechanical ventilation $=37$; days of mechanical ventilation in patient alive at hospital discharge (90 days) $=139$; length of ICU stay in patient alive at ICU discharge (90 days) $=58$; length of hospital stay = 19; length of hospital stay in patient alive at ICU discharge (90 days) $=87 ;$ ICU, 28-day, 60-day, and 90-day mortality $=1$. Participants were adult patients ( $\geq 18$ years) with severe or moderate ARDS who received mechanical ventilation and had tracheostomy. Participants were excluded if they had made the decision to withhold/withdraw treatment; if they had been transferred from another hospital with invasive mechanical ventilation; if they received tracheostomy on the first day of the study period and had been on invasive mechanical ventilation for 6 days or more; or if they had been discharged from the ICU or died in the ICU within 7 days. Length of ICU and hospital stay were calculated from their admission to discharge. Mortality was calculated from day 7 to patient discharge. Days of mechanical ventilation, length of ICU stay, and length of hospital stay were compared using linear regression models, and mortality using logistic regression models. (DOCX $17 \mathrm{~kb}$ )

\section{Abbreviations}

ARDS: Acute respiratory distress syndrome; BMI: Body mass index; ECMO: Extracorporeal membrane oxygenation; ESICM: European Society of Intensive Care Medicine; ICUs: Intensive care units; LUNG-SAFE: Large observational study to understand the global impact of severe acute respiratory failure; $\mathrm{PaCO} 2$ : Partial arterial pressure of carbon dioxide; rWORLD: Non-European rest of world high income countries; SES: Socioeconomic status; SOFA: Sequential organ failure assessment; VFDs: Ventilatorfree days

\section{Acknowledgements}

LUNG SAFE investigators and ESICM Trial Group email address: lungsafe@esicm.org Study coordination: Guy M. Francois (European Society of Intensive Care Medicine, Brussels, Belgium).

Data revision and management: Francesca Rabboni (University of MilanBicocca, Monza, Italy), Fabiana Madotto (University of Milan-Bicocca, Monza, Italy), Sara Conti (University of Milan-Bicocca, Monza, Italy).

LUNG SAFE executive and steering committees: John G. Laffey, Giacomo Bellani, Tai Pham, Eddy Fan, Antonio Pesenti, Laurent Brochard, Andres Esteban, Luciano Gattinoni, Frank van Haren, Anders Larsson, Daniel F. McAuley, Marco Ranieri, Gordon Rubenfeld, B. Taylor Thompson, Hermann Wrigge, Arthur S. Slutsky.

National coordinators: Argentina: Fernando Rios. Australia/New Zealand: Frank Van Haren.

Belgium: T. Sottiaux, P. Depuydt. Bolivia: Fredy S. Lora. Brazil: Luciano Cesar Azevedo. Canada: Eddy Fan. Chile: Guillermo Bugedo. China: Haibo Qiu. Colombia: Marcos Gonzalez.

Costa Rica: Juan Silesky. Czech Republic: Vladimir Cerny. Denmark: Jonas Nielsen. Ecuador: Manuel Jibaja. France: Tài Pham. Germany: Hermann Wrigge. Greece: Dimitrios Matamis. Guatemala: Jorge Luis Ranero. India: Pravin Amin. Iran: S. M. Hashemian. Ireland: Kevin Clarkson. Italy: Giacomo Bellani. Japan: Kiyoyasu Kurahashi. Mexico: Asisclo Villagomez. Morocco: Amine Ali Zeggwagh. The Netherlands: Leo M. Heunks. Norway: Jon Henrik Laake. The Philippines:
Jose Emmanuel Palo. Portugal: Antero do Vale Fernandes. Romania: Dorel Sandesc. Saudi Arabia: Yaasen Arabi. Serbia: Vesna Bumbasierevic. Spain: Nicolas Nin, Jose A. Lorente. Sweden: Anders Larsson. Switzerland: Lise Piquilloud. Tunisia: Fekri Abroug. United Kingdom: Daniel F. McAuley, Lia McNamee. Uruguay: Javier Hurtado.

USA: Ed Bajwa. Venezuela: Gabriel Démpair.

Site investigators by country:

Albania: University Medical Center of Tirana "Mother Theresa" (Tirana): Hektor Sula, Lordian Nunci; University Hospital Shefqet Ndroqi (Tirana): Alma Cani. Argentina: Clinica De Especialidades (Villa Maria): Alan Zazu; Hospital Dr. Julio C. Perrando (Resistencia): Christian Dellera, Carolina S. Insaurralde; Sanatorio Las Lomas (San Isidro, Buenos Aires): Risso V. Alejandro; Sanatorio De La Trinidad San Isidro (San Isidro): Julio Daldin, Mauricio Vinzio; Hospital Español De Mendoza (Godoy Cruz-Mendoza): Ruben O. Fernandez; Hospital Del Centenario (Rosario): Luis P. Cardonnet, Lisandro R. Bettini; San Antonio (Gualeguay [Entre Rios]): Mariano Carboni Bisso, Emilio M. Osman; Cemic (Buenos Aires): Mariano G. Setten, Pablo Lovazzano; Hospital Universitrario Austral (Pilar): Javier Alvarez, Veronica Villar; Hospital Por + Salud (Pami): Dr. Cesar Milstein (Buenos Aires): Norberto C. Pozo, Nicolas Grubissich; Sanatorio Anchorena (Buenos Aires): Gustavo A. Plotnikow, Daniela N. Vasquez; Sanatorio De La Trinidad Miter (Buenos Aires): Santiago llutovich, Norberto Tiribelli; Hospital Luis Lagomaggiore (Mendoza): Ariel Chena, Carlos A. Pellegrini; H.I.G.A. San Martín (La Plata): María G. Saenz, Elisa Estenssoro; Hospital Misericordia (Cordoba): Matias Brizuela, Hernan Gianinetto; Sanatorio Juncal (Temperley): Pablo E. Gomez, Valeria I. Cerrato; Hospital D. F. Santojanni. (Buenos Aires): Marco G. Bezzi, Silvina A. Borello; Hospital Alejandro Posadas (Buenos Aires): Flavia A. Loiacono, Adriana M. Fernandez.

Australia: St. Vincent's Hospital, Sydney (Darlinghurst): Serena Knowles, Claire Reynolds; St. George Public Hospital (Kogarah): Deborah M. Inskip, Jennene J. Miller; Westmead Hospital (Westmead): Jing Kong, Christina Whitehead; Flinders Medical Centre (Bedford Park, South Australia): Shailesh Bihari; John Hunter Hospital (Newcastle): Aylin Seven, Amanda Krstevski; Canberra Hospital (Garran): Helen J. Rodgers, Rebecca T. Millar; Calvary Mater Newcastle (Waratah): Toni E. Mckenna, Irene M. Bailey; Cabrini Hospital (Melbourne): Gabrielle C. Hanlon; Liverpool Hospital (Liverpool): Anders Aneman, Joan M. Lynch; Coffs Harbor Health Campus (Coffs Harbor): Raman Azad, John Neal; Sir Charles Gairdner Hospital (Nedlands): Paul W. Woods, Brigit L. Roberts; Concord Hospital (Concord): Mark R. Kol, Helen S. Wong.

Austria: General Hospital of Vienna/Medical University of Vienna (Vienna): Katharina C. Riss, Thomas Staudinger Belgium: Cliniques universitaires St-LuC, Université Catholique de Louvain (UCL) (Brussels): Xavier Wittebole, Caroline Berghe; CHU Dinant-Godinne (Yvoir): Pierre A. Bulpa, Alain M. Dive; AZ Sint-Augustinus Veurne (Veurne): Rik Verstraete, Herve Lebbinck; Ghent University Hospital (Ghent): Pieter Depuydt, Joris Vermassen; University Hospitals Leuven (Leuven): Philippe Meersseman, Helga Ceunen.

Brazil: Hospital Renascentista (Pouso Alegre): Jonas I. Rosa, Daniel O. Beraldo; Vitoria Apart Hospital (Serra): Claudio Piras, Adenilton M. Rampinelli; Hospital Das Clinicas (São Paulo): Antonio P. Nassar Jr.; Hospital Geral do Grajaù (São Paulo): Sergio Mataloun, Marcelo Moock; Evangelical Hospital (Cachoeiro De Itapemirim/Espírito Santo): Marlus M. Thompson, Claudio H. Gonçalves; Hospital Moinhos De Vento (Porto Alegre): Ana Carolina P. Antônio, Aline Ascoli; Hospital Alvorada Taguatinga (Taguatinga): Rodrigo S. Biondi, Danielle C. Fontenele; Complexo Hospitalar Mngabeira Tarcisio Burity (Joao Pessoa): Danielle Nobrega, Vanessa M. Sales.

Brunei Darussalam: Raja Isteri Pengiran Anak Saleha (Ripas) Hospital (Bandar Seri Begawan): Dr. Suresh Shindhe, Dr. Dayangku Hajah Maizatul Aiman binti Pengiran Haji Ismail.

Canada: Medical-Surgical ICU of St. Michael's Hospital (Toronto): John Laffey, Francois Beloncle; St. Joseph's Health Centre (Toronto): Kyle G. Davies, Rob Cirone; Sunnybrook Health Sciences Center (Toronto): Venika Manoharan, Mehvish Ismail; Toronto Western Hospital (Toronto): Ewan C. Goligher, Mandeep Jassal; Medical Surgical ICU of the Toronto General Hospital (Toronto): Erin Nishikawa, Areej Javeed; Cardiovascular ICU of St. Michael's Hospital (Toronto): Gerard Curley, Nuttapol Rittayamai; Cardiovascular ICU of the Toronto General Hospital (Toronto): Matteo Parotto, Niall D. Ferguson; Mount Sinai Hospital (Toronto): Sangeeta Mehta, Jenny Knoll; Trauma-Neuro ICU of St. Michael's Hospital (Toronto): Antoine Pronovost, Sergio Canestrini Chile: Hospital Clínico Pontificia Universidad Católica De Chile (Santiago): Alejandro R. Bruhn, Patricio H. Garcia; Hospital Militar De Santiago (Santiago): Felipe A. Aliaga, Pamela A. Farías; Clinica Davila (Santiago): Jacob S. Yumha; Hospital Guillermo Grant Benavente (Concepcion): Claudia A. Ortiz, Javier E. 
Salas; Clinica Las Lilas (Santiago): Alejandro A. Saez, Luis D. Vega; Hospital Naval Almirante Nef (Viña Del Mar): Eduardo F. Labarca, Felipe T. Martinez; Hospital Luis Tisné Brousse (Penanolen): Nicolás G. Carreño, Pilar Lora. China: The Second Affiliated Hospital of Harbin Medical University (Harbin): Haitao Liu; Nanjing Zhong-Da Hospital, Southeast University (Nanjing): Haibo Qiu, Ling Liu; The First Affiliated Hospital of Anhui Medical University (Hefei): Rui/Tang, Xiaoming Luo; Peking University People's Hospital (Beijing): Youzhong An, Huiying Zhao; Fourth Affiliated Hospital of Harbin Medical University (Harbin): Yan Gao, Zhe Zhai; Nanjing Jiangbei People's Hospital Affiliated to Medical School of Southeast University (Nanjing): Zheng L. Ye, Wei Wang; The First Affiliated Hospital of Dalian Medical Unvercity (Dalian): Wenwen Li, Qingdong Li; Subei People's Hospital of Jiangsu Province (Yanghzou): Ruiqiang Zheng; Jinling Hospital (Nanjing): Wenkui Yu, Juanhong Shen; Urumqi General Hospital (Urumqi): Xinyu Li; Intensive Care Unit, First Affiliated Hospital of Wannan Medical College, Yijishan Hospital (Wuhu): Tao Yu, Weihua Lu; Sichuan Provincial People's Hospital (Chengdu): Ya Q. Wu, Xiao B. Huang; Hainan Province People's Hospital (Haikou): Zhenyang He; People's Hospital of Jiangxi Province (Nanchang): Yuanhua Lu; Qilu Hospital of Shandong University (Jinan): Hui Han, Fan Zhang; Zhejiang Provincial People's Hospital (Hangzhou): Renhua Sun; The First Affiliated Hospital of Bengbu Medical College (Bengbu, Anhui): Hua X. Wang, Shu H. Qin; Nanjing Municipal Government Hospital (Nanjing): Bao H. Zhu, Jun Zhao; The First Hospital of Lanzhou University (Lanzhou): Jian Liu, Bin Li; The First Affiliated Hospital of Chongqing University of Medical Science (Chongqing): Jing L. Liu, Fa C. Zhou; Xuzhou Central Hospital, Jiangsu Province, China (Xuzhou): Qiong J. Li, Xing Y. Zhang; The First People's Hospital of Foshan (Foshan): Zhou Li-Xin, Qiang Xin-Hua; The First Affiliated Hospital of Guangxi Medical University (Nanning): Liangyan Jiang; Renji Hospital, Shanghai Jiao Tong University School of Medicine (Shanghai): Yuan N. Gao, Xian Y. Zhao; First Hospital of Shanxi Medical University (Taiyuan): Yuan Y. Li, Xiao L. Li; Shandong Provincial Hospital (Jinan): Chunting Wang, Qingchun Yao; Fujian Provincial Hospital (Fuzhou): Rongguo Yu, Kai Chen; Henan Provincial People's Hospital (Zhengzhou): Huanzhang Shao, Bingyu Qin; The Second Affiliated Hospital of Kunming Medical University (Kunming City): Qing Q. Huang, Wei H. Zhu; Xiangya Hospital, Central South University (Changsha): Ai Y. Hang, Ma X. Hua; The First Affiliated Hospital of Guangzhou Medical University (Guangzhou): Yimin Li, Yonghao Xu; People's Hospital of Hebei Province (Shijiazhuang): Yu D. Di, Long L. Ling; Guangdong General Hospital (Guangzhou): Tie H. Qin, Shou H. Wang; Beijing Tongren Hospital (Beijing): Junping Qin; Jiangsu Province Hospital (Nanjing): Yi Han, Suming Zhou Colombia: Fundación Valle Del Lili (Cali): Monica P. Vargas.

Costa Rica: Hospital San Juan De Dios (San José): Juan I. Silesky Jimenez, Manuel A. González Rojas, Jaime E. Solis-Quesada, Christian M. Ramirez-Alfaro Czech Republic: University Hospital of Ostrava (Ostrava): Jan Máca, Peter Sklienka. Denmark: Aarhus Universitetshospital (Aarhus N): Jakob Gjedsted, Aage Christiansen; Rigshopitalet: Jonas Nielsen.

Ecuador: Hospital Militar (Quito): Boris G. Villamagua, Miguel Llano. France: Clinique du Millenaire (Montpellier): Philippe Burtin, Gautier Buzancais; Centre Hospitalier (Roanne): Pascal Beuret, Nicolas Pelletier; $\mathrm{CHU}$ d'Angers (Angers): Satar Mortaza, Alain Mercat; Hôpital Marc Jacquet (Melun): Jonathan Chelly, Sébastien Jochmans; CHU Caen (Caen): Nicolas Terzi, Cédric Daubin; Henri Mondor Hospital (Créteil): Guillaume Carteaux, Nicolas de Prost; Cochin Hospital (Paris): Jean-Daniel Chiche, Fabrice Daviaud; Hôpital Tenon (Paris): Tai Pham, Muriel Fartoukh; CH Mulhouse-Emile Muller (Mulhouse): Guillaume Barberet, Jerome Biehler; Archet 1 University Hospital (Nice): Jean Dellamonica, Denis Doyen; Hopital Sainte Musse (Toulon): Jean-Michel Arnal, Anais Briquet; Hopital Nord - Réanimation des Détresses Respiratoires et Infections Sévères (Marseille): Sami Hraiech, Laurent Papazian; HEGP (Paris): Arnaud Follin; Louis Mourier Hospital (Colombes): Damien Roux, Jonathan Messika; Centre Hospitalier de Dax (Dax): Evangelos Kalaitzis; Réanimation Médicale, GH Pitié- Salpêtrière (Paris): Laurence Dangers, Alain Combes; AP-HP Ambroise Paré (Boulogne- Billancourt): Siu-Ming Au; University Hospital Rouen (Rouen): Gaetan Béduneau, Dorothée Carpentier; CHU Amiens (Amiens-Salouel): Elie H. Zogheib, Herve Dupont; Centre Hospitalier Intercommunal Robert Ballanger (Aulnay Sous Bois): Sylvie Ricome, Francesco L. Santoli; Centre Hospitalier René Dubos (Pontoise): Sebastien L. Besset; CHI Portes de l'Oise (Beaumont Sur Oise): Philippe Michel, Bruno Gelée; Archet 2 University Hospital (Nice): Pierre-Eric Danin, Bernard Goubaux; Centre Hospitalier Pierre Oudot (Bourgoin Jallieu): Philippe J. Crova, Nga T. Phan; CH Dunkerque (Dunkerque): Frantz Berkelmans; Centre Hospitalier de Belfort Montbéliard (Belfort): Julio C. Badie, Romain Tapponnier; Centre Hospitalier Emile Muller
(Mulhouse): Josette Gally, Samy Khebbeb; Hôpital de Hautepierre-Hôpitaux Universitaires de Strasbourg (Strasbourg): Jean-Etienne Herbrecht, Francis Schneider; Centre Hospitalier de Dieppe (Dieppe): Pierre-Louis M Declercq, Jean-Philippe Rigaud; Bicetre (Le Kremin-Bicetre): Jacques Duranteau, Anatole Harrois; CHU Gabriel Montpied (Clermont-Ferrand): Russell Chabanne, Julien Marin; CHU Estaing (Clermont-Ferrand): Charlene Bigot, Sandrine Thibault; CHI Eure-Seine Evreux (Evreux): Mohammed Ghazi, Messabi Boukhazna; Centre Hospitalier d Châlons en Champagne (Châlons en Champagne): Salem Ould Zein; CH Beauvais (Beauvais): Jack R. Richecoeur, Daniele M. Combaux; Centre Hospitalier Le Mans (Le Mans): Fabien Grelon, Charlene Le Moal; Hôpital Fleyriat (Bourg en Bresse): Elise P. Sauvadet, Adrien Robine; Hôpital Saint Louis (Paris): Virginie Lemiale, Danielle Reuter; Service de Pneumologie Pitié-Salpétrière (Paris): Martin Dres, Alexandre Demoule; Centre Hospitalier Gonesse (Gonesse): Dany Goldgran-Toledano; Hôpital Croix Rousse (Lyon): Loredana Baboi, Claude Guérin. Germany: St. Nikolaus-Stiftshospital (Andernach): Ralph Lohner; Fachkrankenhaus Coswig GmbH (Coswig): Jens Kraßler, Susanne Schäfer; University Hospital Frankfurt (Frankfurt am Main): Kai D. Zacharowski, Patrick Meybohm; Department of Anesthesia \& Intensive Care Medicine, University Hospital of Leipzig (Leipzig): Andreas W. Reske, Philipp Simon; Asklepios Klinik Langen (Langen): Hans-Bernd F Hopf, Michael Schuetz; Städtisches Krankenhaus Heinsberg (Heinsberg): Thomas Baltus.

Greece: Hippokrateion General Hospital of Athens (Athens): Metaxia N. Papanikolaou, Theonymfi G. Papavasilopoulou; University General Hospital of Thessaloniki AHEPA (Thessaloniki): Giannis A. Zacharas, Vasilis Ourailogloy; Hippokration General Hospital of Thessaloniki (Thessaloniki): Eleni K. Mouloudi, Eleni V. Massa; Hospital General of Kavala (Kavala): Eva O. Nagy, Electra E. Stamou; Papageorgiou General Hospital (Thessaloniki): Ellada V. Kiourtzieva, Marina A. Oikonomou.

Guatemala: Hospital General De Enfermedades, Instituto Guatemalteco De Seguridad Social (Ciudad De Guatemala): Luis E. Avila; Centro Médico Militar (Guatemala): Cesar A. Cortez, Johanna E. Citalán.

India: Deenanath Mangeshkar Hospital and Research Center (Pune): Sameer A. Jog, Safal D. Sable; Care Institute of Medical Sciences (CIMS) Hospital (Ahmedabad): Bhagyesh Shah; Sanjay Gandhi Postgraduate Institute of Medical Sciences (SGPGIMS) (Lucknow): Mohan Gurjar, Arvind K. Baronia; Rajasthan Hospital (Ahmedabad): Mohammedfaruk Memon; National Institute of Mental Health and Neuro Sciences (NIMHANS) (Bangalore): Radhakrishnan Muthuchellappan, Venkatapura J. Ramesh; Anaesthesiology Unit of the Kasturba Medical College \& Department of Respiratory Therapy, SHOAS, Manipal University (Manipal): Anitha Shenoy, Ramesh Unnikrishnan; Sanjeevan Hospital (Pune): Subhal B. Dixit, Rachana V. Rhayakar; Apollo Hospitals (Chennai): Nagarajan Ramakrishnan, Vallish K. Bhardwaj; Medicine Unit of the Kasturba Medical College and Department of Respiratory Therapy, SHOAS, Manipal University (Manipal): Heera L. Mahto, Sudha V. Sagar; G. Kuppuswamy Naidu Memorial Hospital (Coimbatore): Vijayanand Palaniswamy, Deeban Ganesan.

Iran: NRITLD/Masih Daneshvari (Tehran): Seyed Mohammadreza Hashemian, Hamidreza Jamaati; Milad Hospital (Tehran): Farshad Heidari. Ireland: St. Vincent's University Hospital (Dublin): Edel A. Meaney, Alistair Nichol; Mercy University Hospital (Cork): Karl M. Knapman, Donall O'Croinin; Cork University Hospital (Cork): Eimhin S. Dunne, Dorothy M. Breen; Galway University Hospital (Galway): Kevin P. Clarkson, Rola F. Jaafar; Beaumont Hospital (Dublin): Rory Dwyer, Fahd Amir; Mater Misericordiae University Hospital (Dublin): Olaitan O. Ajetunmobi, Aogan C. O'Muircheartaigh; Tallaght Hospital (Dublin): Colin S. Black, Nuala Treanor; St. James's Hospital (Dublin): Daniel V. Collins, Wahid Altaf.

Italy: Santa Maria delle Croci Hospital (Ravenna): Gianluca Zani, Maurizio Fusari; Arcispedale Sant'Anna Ferrara (Ferrara): Savino Spadaro, Carlo A. Volta; Ospedale Profili (Fabriano [An]): Romano Graziani, Barbara Brunettini; Umberto I Nocera Inferiore (Nocera Inferiore Salerno): Salvatore Palmese; Azienda Ospedaliera San Paolo - Polo Universitario, Università degli Studi di Milano (Milan): Paolo Formenti, Michele Umbrello; Sant'Anna (San Fermo Della Battaglia [Co]): Andrea Lombardo; Spedali Civili Brescia (Brescia): Elisabetta Pecci, Marco Botteri; Fondazione IRCCS Ca'Granda, Ospedale Maggiore Policlinico (Milan): Monica Savioli, Alessandro Protti; University Campus Bio-Medico of Rome (Rome): Alessia Mattei, Lorenzo Schiavoni; Azienda Ospedaliera "Mellino Mellini" (Chiari [Bs]): Andrea Tinnirello, Manuel Todeschini; Policlinico P. Giaccone, University of Palermo (Palermo): Antonino Giarratano, Andrea Cortegiani; Niguarda Cà Granda Hospital (Milan): Sara Sher, Anna Rossi; A.Gemelli University Hospital (Rome): Massimo M. Antonelli, Luca M. Montini; Ospedale "Sandro Pertini" (Rome): Paolo Casalena, Sergio 
Scafetti; ISMeTT IRCCS UPMC (Palermo): Giovanna Panarello, Giovanna Occhipinti; Ospedale San Gerardo (Monza): Nicolò Patroniti, Matteo Pozzi; Santa Maria Della Scaletta (Imola): Roberto R. Biscione, Michela M. Poli; Humanitas Research Hospital (Rozzano): Ferdinando Raimondi, Daniela Albiero; Ospedale Desio Azienda Ospedaliera Desio-Vimercate (Desio): Giulia Crapelli, Eduardo Beck; Pinetagrande Private Hospital (Castelvolturno): Vincenzo Pota, Vincenzo Schiavone; IRCCS Azienda Ospedaliera Universitaria San Martino - IST (Genova): Alexandre Molin, Fabio Tarantino; Ospedale San Raffaele (Milano): Giacomo Monti, Elena Frati; Ospedali Riuniti Di Foggia (Foggia): Lucia Mirabella, Gilda Cinnella; Azienda Ospedaliera Luigi Sacco - Polo Universitario (Milano): Tommaso Fossali, Riccardo Colombo; A.O.U. Città della Salute e della Scienza di Torino (Turin): Pierpaolo Terragni Ilaria Pattarino; Università degli Studi di Pavia - Fondazione IRCCS Policlinico San Matteo (Pavia): Francesco Mojoli, Antonio Braschi; Azienda Ospedaliera Ospedale Civile Legnano (Legnano): Erika E. Borotto; Arnas Ospedale Civico Di Cristina Benfratelli (Palermo): Andrea N. Cracchiolo, Daniela M. Palma; Azienda Ospedaliera Della Provincia Di Lecco - Ospedale "A. Manzoni" (Lecco): Francesco Raponi, Giuseppe Foti; A.O. Provincia Di Lecco - Ospedale Alessandro Manzoni (Lecco): Ettore R. Vascotto, Andrea Coppadoro; Cliniche Universitarie Sassari (Sassari): Luca Brazzi, Leda Floris; IRCCS Policlinico San Matteo (Pavia): Giorgio A. lotti, Aaron Venti. Japan: Yokohama City University Hospital (Yokohama): Osamu Yamaguchi, Shunsuke Takagi; Toyooka Hospital (Toyooka City, Hyogo Prefecture): Hiroki N. Maeyama; Chiba University Hospital (Chiba City): Eizo Watanabe, Yoshihiro Yamaji; Okayma University Hospital (Okayama): Kazuyoshi Shimizu, Kyoko Shiozaki; Japanese Foundation for Cancer Research, Cancer Institute Hospital, Department of Emergency Medicine and Critical Care (Tokyo): Satoru Futami; Ibaraki Prefectural Central Hospital (Kasama): Sekine Ryosuke; Tohoku University Hospital (Sendai-Shi): Koji Saito, Yoshinobu Kameyama; Tokyo Medical University Hachioji Medical Center (Hachioji, Tokyo): Keiko Ueno; Tokushima University Hospital (Tokushima): Masayo Izawa, Nao Okuda; Maebashi Red Cross Hospital (Gunma Maebashi): Hiroyuki Suzuki, Tomofumi Harasawa; Urasoe General Hospital (Urasoe): Michitaka Nasu, Tadaaki Takada; Ohta General Hospital Foundation Ohta Nishinouchi Hospital (Fukushima): Fumihito Ito; Jichi Medical University Hospital (Shimotsuke): Shin Nunomiya, Kansuke Koyama; Mito Kyodo General Hospital, Tsukuba University Hospital Mito Medical Center (Mito): Toshikazu Abe; Sendai City Hospital (Sendai): Kohkichi Andoh, Kohei Kusumoto; Ja Hiroshima General Hospital (Hatsukaichi City, Hiroshima): Akira Hirata, Akihiro Takaba; Yokohama Rosai Hospital (Yokohama): Hiroyasu Kimura; Nagasaki University Hospital (Nagasaki): Shuhei Matsumoto, Ushio Higashijima; Niigata University Medical \& Dental Hospital (Niigata): Hiroyuki Honda, Nobumasa Aoki; Mie University Hospital (Tsu, Mie): Hiroshi Imai; Yamaguchi University Hospital (Ube, Yamaguchi): Yasuaki Ogino, Ichiko Mizuguchi; Saiseikai Kumamoto Hospital (Kumamoto City): Kazuya Ichikado; Shinshu University School of Medecine (Matsumoto City): Kenichi Nitta, Katsunori Mochizuki; Kuki General Hospital (Kuki): Tomoaki Hashida; Kyoto Medical Center (Kyoto): Hiroyuki Tanaka; Fujita Health University (Toyoake): Tomoyuki Nakamura, Daisuke Niimi; Rakwakai Marutamachi Hospital (Kyoto): Takeshi Ueda; Osaka University Hospital (Suita City, Osaka Prefecture): Yozo Kashiwa, Akinori Uchiyama.

Latvia: Paul Stradins Clinical University Hospital (Riga): Olegs Sabelnikovs, Peteris Oss Lebanon: Kortbawi Hospital (Jounieh): Youssef Haddad. Malaysia: Hospital Kapit (Kapit): Kong Y. Liew.

Mexico: Instituto Nacional De Cancerología, México (Mexico City): Silvio A. Ñamendys-Silva, Yves D. Jarquin-Badiola; Hospital De Especialidades "Antonio Fraga Mouret" Centro Medico Nacional La Raza IMSS (Mexico City): Luis A. Sanchez-Hurtado, Saira S. Gomez-Flores; Hospital Regional $1^{\circ}$ De Octubre (Mexico City): Maria C. Marin, Asisclo J. Villagomez; Hospital General. Dr. Manuel Gea Gonzalez (Mexico City): Jordana S. Lemus, Jonathan M. Fierro; Hospital General De Zona No. 1 Instituto Mexicano Del Seguro Social Tepic Nayarit (Tepic): Mavy Ramirez Cervantes, Francisco Javier Flores Mejia; Centro Medico Dalinde (Mexico D.F.): Dulce Dector, Dulce M. Dector; OPD Hospital Civil De Guadalajara Hospital Juan I. Menchaca (Guadalajara): Daniel R. Gonzalez, Claudia R. Estrella; Hospital Regional De Ciudad Madero Pemex (Ciudad Madero): Jorge R. Sanchez-Medina, Alvaro Ramirez-Gutierrez; Centro Médico ABC (Mexico D.F.): Fernando G. George, Janet S. Aguirre; Hospital Juarez De Mexico (Mexico City): Juan A. Buensuseso, Manuel Poblano. Morocco: Mohammed V University, University Teaching Ibn Sina Hospital (Rabat): Tarek Dendane, Amine Ali Zeggwagh; Hopital Militaire D'Instruction Mohammed V (Rabat): Hicham Balkhi; Errazi (Marrakech): Mina Elkhayari, Nacer Samkaoui; University Teaching Hospital Ibn Rushd (Casablanca): Hanane Ezzouine, Abdellatif Benslama; Hôpital des Spécialités de Rabat (HSR) (Rabat): Mourad Amor, Wajdi Maazouzi.
The Netherlands: Tjongerschans (Heerenveen): Nedim Cimic, Oliver Beck; CWZ (Nijmegen): Monique M. Bruns, Jeroen A. Schouten; Rijnstate Hospital (Arnhem): Myra - Rinia, Monique Raaijmakers; Radboud UMC (Nijmegen): Leo M. Heunks, Hellen M. Van Wezel; Maastricht University Medical Centre (Maastricht): Serge J. Heines, Ulrich Strauch; Catharinaziekenhuis (Eindhoven): Marc P. Buise; Academic Medical Center (Amsterdam): Fabienne D. Simonis, Marcus J. Schultz.

New Zealand: Tauranga Hospital (Tauranga): Jennifer C. Goodson, Troy S. Browne; Wellington Hospital (Wellington): Leanlove Navarra, Anna Hunt; Dunedin Hospital (Dunedin): Robyn A. Hutchison, Mathew B. Bailey; Auckland City Hospital (Auckland): Lynette Newby, Colin Mcarthur; Whangarei Base Hospital (Whangarei): Michael Kalkoff, Alex Mcleod; North Shore Hospital (Auckland): Jonathan Casement, Danielle J. Hacking.

Norway: Ålesund Hospital (Ålesund): Finn H. Andersen, Merete S. Dolva; Oslo University Hospital Rikshospitalet Medical Center (Oslo): Jon H. Laake, Andreas Barratt-Due; Stavanger University Hospital (Stavanger): Kim Andre L. Noremark, Eldar Søreide; Haukeland University Hospital (Bergen): Brit Å. Sjøbø, Anne B. Guttormsen.

Peru: Hospital Nacional Edgardo Rebagliati Martins (Lima): Hector H. Leon Yoshido; Clínica Ricardo Palma (Lima): Ronald Zumaran Aguilar, Fredy A. Montes Oscanoa.

The Philippines: The Medical City (Pasig): Alain U. Alisasis, Joanne B. Robles; Chong Hua Hospital (Cebu): Rossini Abbie B. Pasanting-Lim, Beatriz C. Tan Poland: Warsaw University Hospital (Warsaw): Pawel Andruszkiewicz, Karina Jakubowska.

Portugal: Centro Hospitalar da Cova da Beira (Covilhã): Cristina M. Coxo; Hospital Santa Maria, Centro Hospitalar Lisboa Norte (Lisboa): António M. Alvarez, Bruno S. Oliveira; Centro Hospitalar Trás-os-Montes e Alto Douro Hospital de S. Pedro - Vila Real (Vila Real): Gustavo M. Montanha, Nelson C. Barros; Hospital Beatriz Ângelo (Loures): Carlos S. Pereira, António M. Messias; Hospital de Santa Maria (Lisboa): Jorge M. Monteiro; Centro Hospitalar Médio Tejo - Hospital De Abrantes (Abrantes): Ana M. Araujo, Nuno T. Catorze; Instituto Português de Oncologia de Lisboa (Lisboa): Susan M. Marum, Maria J. Bouw; Hospital Garcia De Orta (Almada): Rui M. Gomes, Vania A. Brito; Centro Hospitalar do Algarve (Faro): Silvia Castro, Joana M. Estilita; HPP Hospital De Cascais (Alcabideche):

Filipa M. Barros; Hospital Prof. Doutor Fernando Fonseca Epe (Amadora): Isabel M. Serra, Aurelia. Romania: Fundeni Clinical Institute (Bucharest): Dana R. Tomescu, Alexandra Marcu; Emergency Clinical County Hospital Timisoara (Timisoara): Ovidiu H. Bedreag, Marius Papurica; Elias University Emergency Hospital (Bucharest): Dan E. Corneci, Silvius loan Negoita.

Russian Federation: University Hospital (Kemerovo): Evgeny Grigoriev; Krasnoyarsk Regional Hospital, Krasnoyarsk State Medical University (Krasnoyarsk): Alexey I. Gritsan, Andrey A. Gazenkampf.

Saudi Arabia: GICU of PSMMC (Riyadh): Ghaleb Almekhlafi, Mohamad M. Albarrak; SICU of PSMMC (Riyadh): Ghanem M. Mustafa; King Faisal Hospital and Research Center (Riyadh): Khalid A. Maghrabi, Nawal Salahuddin; King Fahad Hospital (Baha): Tharwat M. Aisa; King Abdulaziz Medical City (Riyadh): Ahmed S. Al Jabbary, Edgardo Tabhan; King Abdulaziz Medical City (Riyadh): Yaseen M. Arabi; King Abdulaziz Medical City (Riyadh): Yaseen M. Arabi, Olivia A. Trinidad; King Abdulaziz Medical City (Riyadh): Hasan M. Al Dorzi, Edgardo E. Tabhan.

South Africa: Charlotte Maxeke Johannesburg Academic Hospital (Johannesburg): Stefan Bolon, Oliver Smith.

Spain: Hospital Sant Pau (Barcelona): Jordi Mancebo, Hernan Aguirre-Bermeo; Hospital Universitari Bellvitge (L'Hospitalet de Llobregat (Barcelona)): Juan C. Lopez-Delgado, Francisco Esteve; Hospital Son Llatzer (Palma de Mallorca): Gemma Rialp, Catalina Forteza; Sabadell Hospital, CIBER Enfermedades Respiratorias (Sabadell): Candelaria de Haro, Antonio Artigas; Hospital Universitario Central de Asturias (Oviedo): Guillermo M. Albaiceta, Sara de Cima- Iglesias; Complejo Hospitalario Universitario de A Coruña (A Coruña): Leticia Seoane-Quiroga, Alexandra Ceniceros-Barros; Hospital Universitario Miguel Servet (Zaragoza): Antonio L. Ruiz- Aguilar, Luis M. Claraco-Vega; Morales Meseguer University Hospital (Murcia): Juan Alfonso Soler, Maria del Carmen Lorente; Hospital Universitario del Henares (Coslada): Cecilia Hermosa, Federico Gordo; Complejo Asistencial de Palencia. Hospital Rio Carrión (Palencia): Miryam Prieto-González, Juan B. López-Messa; Fundación Jiménez Díaz (Madrid): Manuel P. Perez, Cesar P. Perez; Hospital Clínico Universitario Lozano Blesa (Zaragoza): Raquel Montoiro Allue; Hospital Verge de la Cinta (Tortosa): Ferran Roche-Campo, Marco Ibañez-Santacruz; Hospital Universitario 12 de Octubre (Madrid): Susana Temprano; Hospital 
Universitario Príncipe de Asturias (Alcalá de Henares, Madrid): Maria C. Pintado, Raul de Pablo; Hospital Universitari Germans Trias i Pujol (Badalona): Pilar Ricart Aroa Gómez; Hospital Universitario Arnau de Vilanova de Lleida (Lleida): Silvia Rodriguez Ruiz, Silvia Iglesias Moles; Consorci Sanitari de Terrassa - Hospital de Terrassa (Barcelona): Maria Teresa Jurado, Alfons Arizmendi; Hospital Universitari Mútua Terrassa (Terrassa): Enrique A. Piacentini; Hospital Universitario de Móstoles (Mostoles): Nieves Franco, Teresa Honrubia; Complejo Asistencial de Salamanca (Salamanca): Meisy Perez Cheng, Elena Perez Losada; Hospital General Universitario de Ciudad Real (Ciudad Real): Javier Blanco, Luis J. Yuste; Torrecardenas (Almeria): Cecilia Carbayo-Gorriz, Francisca G. CazorlaBarranquero; Hospital Universitario Donostia (San Sebastian): Javier G. Alonso, Rosa S. Alda; Hospital Universitario de Torrejón (Madrid): Ángela Algaba, Gonzalo Navarro; Hospital Universitario de La Princesa (Madrid): Enrique Cereijo, Esther Diaz-Rodriguez; Hospital Universitario Lucus Augusti (Lugo): Diego Pastor Marcos, Laura Alvarez Montero; Hospital Universitario Santa Lucia (Cartagena): Luis Herrera Para, Roberto Jimenez Sanchez; Hospital Universitario Severo Ochoa, Leganes (Madrid): Miguel Angel Blasco Navalpotro, Ricardo Diaz Abad; University Hospital of Nuestra Señora de Candelaria (Santa Cruz de Tenerife): Raquel Montiel González, Dácil Parrilla Toribio; Hospital Universitario Marques de Valdecilla (Santander): Alejandro G. Castro, Maria Jose D. Artiga; Hospital Infanta Cristina (Parla, Madrid): Oscar Penuelas; Hospital General de Catalunya (Sant Cugat Del Valles): Tomas P. Roser, Moreno F. Olga; San Pedro de Alcántara (Cáceres): Elena Gallego Curto, Rocío Manzano Sánchez; Sant Joan de Reus (Reus): Vallverdu P. Imma, Garcia M. Elisabet; Hospital Joan XXIII (Tarragona): Laura Claverias, Monica Magret; Hospital Universitario de Getafe (Madrid): Ana M. Pellicer, Lucia L. Rodriguez; Hospital Universitario Río Hortega (Valladolid): Jesús Sánchez-Ballesteros, Ángela González-Salamanca; Hospital Arquitecto Marcide (Ferrol, A Coruña): Antonio G. Jimenez, Francisco P. Huerta; Hospital General Universitario Gregorio Marañón (Madrid): Juan Carlos J. Sotillo Diaz, Esther Bermejo Lopez; Hospital General de Segovia (Segovia): David D. Llinares Moya, Alec A. Tallet Alfonso; Hospital General Universitario Reina Sofia (Murcia): Palazon Sanchez Eugenio Luis, Palazon Sanchez Cesar; Complejo Hospitalario Universitario de Albacete (Albacete): Sánchez I. Rafael, Corcoles G. Virgilio; Hospital Infanta Elena (Valdemoro): Noelia N. Recio. Sweden: Sahlgrenska University Hospital (Gothenburg): Richard O. Adamsson, Christian C. Rylander; Karolinska University Hospital (Stockholm): Bernhard Holzgraefe, Lars M. Broman; Akademiska Sjukhuset Uppsala (Uppsala): Joanna Wessbergh, Linnea Persson; Vrinnevisjukhuset (Norrköping): Fredrik Schiöler, Hans Kedelv; Linkoping University Hospital (Linköping): Anna Oscarsson

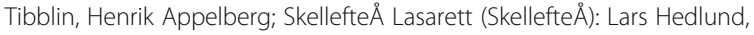
Johan Helleberg; Karolinska University Hospital Solna (Stockholm): Karin E.

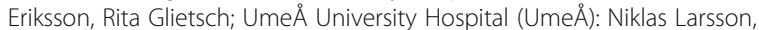
Ingela Nygren; Danderyd Hospital (Stockholm): Silvia L. Nunes, Anna-Karin Morin; Lund Uni- versity Hospital (Lund): Thomas Kander, Anne Adolfsson. Switzerland: CHUV (Centre hospitalier universitaire vaudois) (Lausanne): Lise Piquilloud; Hôpital neuchâtelois - La Chaux-de-Fonds (La Chaux-de-Fonds): Hervé O. Zender, Corinne Leemann-Refondini.

Tunisia: Hopital Taher Sfar Mahdia (Mahdia): Souheil Elatrous; University Hospital Farhat Hached Sousse (Sousse): Slaheddine Bouchoucha, Imed Chouchene; CHU F. Bourguiba (Monastir): Islem Ouanes; Mongi Slim University Hospital, La Marsa (La Marsa): Asma Ben Souissi, Salma Kamoun Turkey: Cerrahpasa Medical Faculty Emergency Intensive Care Unit (Istanbul): Oktay Demirkiran; Cerrahpasa Medical Faculty Sadi Sun Intensive Care Unit (Istanbul): Mustafa Aker, Emre Erbabacan; Uludag University Medical Faculty (Bursa): Ilkay Ceylan, Nermin Kelebek Girgin; Ankara University Faculty of Medicine, Reanimation, Level 3 ICU (Ankara): Menekse Ozcelik, Necmettin Ünal; Ankara University Faculty of Medicine, Level 2 ICU-Postoperative ICU (Ankara): Basak Ceyda Meco; Istanbul Kartal Eğitim ve Araştırma Hastanesi (Istanbul): Onat O. Akyol, Suleyman S. Derman.

UK: Papworth Hospital (Cambridge): Barry Kennedy, Ken Parhar; Royal Glamorgan Hospital (Llantrisant): Latha Srinivasa; Royal Victoria Hospital-Belfast (Belfast): Lia McNamee, Danny McAuley; Jack Steinberg Critical Care Unit, King's College London (London): Phil Hopkins, Clare Mellis; Frank Stansil Critical Care Unit, King's College Hospital (London): Vivek Kakar; Liver ICU of King's College London (London): Dan Hadfield; Christine Brown Critical Care Unit, King's College London (London): Andre Vercueil; West Suffolk Hospital (Bury. St. Edmunds): Kaushik Bhowmick, Sally K. Humphreys; Craigavon Area Hospital (Portadown): Andrew Ferguson, Raymond Mckee; Barts Health NHS Trust, Whipps Cross Hospital (Leytonstone): Ashok S. Raj, Danielle A. Fawkes; Kettering General Hospital, Foundation NHS Trust (Northamptonshire): Philip
Watt, Linda Twohey; Barnet General Hospital (Barnet): Rajeev R. JhaMatthew Thomas, Alex Morton, Varsha Kadaba; Rotherham General Hospital (Rotherham): Mark J. Smith, Anil P. Hormis; City Hospital (Birmingham): Santhana G. Kannan, Miriam Namih; Poole Hospital NHS Foundation Trust (Poole): Henrik Reschreiter, Julie Camsooksai; Weston General Hospital (Weston-Super-Mare): Alek Kumar, Szabolcs Rugonfalvi; Antrim Area Hospital (Antrim): Christopher Nutt, Orla Oneill; Aintree University Hospital (Liverpool): Colette Seasman, Ged Dempsey; Northern General Hospital (Sheffield): Christopher J. Scott, Helen E. Ellis; John Radcliffe Hospital (Oxford): Stuart Mckechnie, Paula J. Hutton; St. George's Hospital (London): Nora N. Di Tomasso, Michela N. Vitale; Hillingdon Hospital (Uxbridge): Ruth Griffin, Michael N. Dean; The Royal Bournemouth \& Christchurch NHS Foundation Trust (Bournemouth, Dorset): Julius H. Cranshaw, Emma L. Willett; Severe Respiratory Failure Service, Guy's and St. Thomas' NHS Foundation Trust (London): Nicholas loannou; Whittington Hospital (London): Sarah Gillis; Wexham Park Hospital (Slough): Peter Csabi; Western General Hospital (Edinburgh): Rosaleen Macfadyen, Heidi Dawson; Royal Preston Hospital (Preston): Pieter D. Preez, Alexandra J. Williams; Brighton and Sussex University Hospitals NHS Trust (Brighton): Owen Boyd, Laura Ortiz-Ruiz de Gordoa; East and North Herts NHS Trust (Stevenage): Jon Bramall, Sophie Symmonds; Barnsley Hospital (Barnsley): Simon K. Chau, Tim Wenham; Prince Charles Hospital (Merthyr Tydfil): Tamas Szakmany, Piroska Toth-Tarsoly; University Hospital of South Manchester NHS Foundation Trust (Manchester): Katie H. Mccalman, Peter Alexander; Harrogate District Hospital (Harrogate): Lorraine Stephenson, Thomas Collyer; East and North Herts NHS Trust (Welwyn Garden City): Rhiannon Chapman, Raphael Cooper; Western Infirmary (Glasgow): Russell M. Allan, Malcolm Sim; Dumfries and Galloway Royal Infirmary (Dumfries): David W. Wrathall, Donald A. Irvine; Charing Cross Hospital (London): Kim S. Zantua, John C. Adams; Worcestershire Royal Hospital (Worcester): Andrew J. Burtenshaw, Gareth P. Sellors; Royal Liverpool University Hospital (Liverpool): Ingeborg D. Welters, Karen E. Williams; Royal Alexandra Hospital (Glasgow): Robert J. Hessell, Matthew G. Oldroyd; Morriston Hospital (Swansea): Ceri E. Battle, Suresh Pillai; Frimley Park Hospita (Frimley): Istvan - Kajtor, Mageswaran - Sivashanmugavel; Altnagelvin Hospital (Derry): Sinead C. Okane, Adrian Donnelly; Buckinghamshire Healthcare NHS Trust (High Wycombe, Buckinghamshire): Aniko D. Frigyik, Jon P. Careless; Milton Keynes Hospital (Milton Keynes): Martin M. May, Richard Stewart; Ulster Hospital (Belfast): T. John Trinder, Samantha J. Hagan; University Hospital of Wales (Cardiff): Matt P. Wise, Jade M. Cole; Freeman Hospital (Newcastle Upon Tyne): Caroline C. MacFie, Anna T. Dowling. Uruguay: Hospital Español (Montevideo): Javier Hurtado, Nicolás Nin; Cudam (Montevideo): Javier Hurtado; Sanatorio Mautone (Maldonado): Edgardo Nuñez; Sanatorio Americano (Montevideo): Gustavo Pittini, Ruben Rodriguez; Hospital de Clínicas (Montevideo): María C Imperio, Cristina Santos; Circulo Católico Obreros Uruguay - Sanatorio Juan Pablo II (Montevideo): Ana G. França, Alejandro Ebeid; CASMU (Montevideo): Alberto Deicas, Carolina Serra USA: St. Louis University Hospital (St. Louis, MO): Aditya Uppalapati, Ghassan Kamel; Beth Israel Deaconess Medical Center (Boston, MA): Valerie M. BannerGoodspeed, Jeremy R. Beitler; Memorial Medical Center (Springfield, IL): Satyanarayana Reddy Mukkera, Shreedhar Kulkarni; Massachusetts General Hospital (Boston, MA): Jarone Lee, Tomaz Mesar; University of Cincinnati Medical Center (Cincinnati, OH): John O Shinn lii, Dina - Gomaa; Massachusetts General Hospital (Boston, MA): Christopher Tainter, Jarone Lee; Massachusetts General Hospital (Boston, MA): Tomaz Mesar, Jarone Lee; R. Adams Cowley Shock Trauma Center, University of Maryland Medical Center (Baltimore, MD): Dale J. Yeatts, Jessica Warren; Intermountain Medical Center (Murray, UT): Michael J. Lanspa, Russel R. Miller, Colin K. Grissom, Samuel M. Brown; Mayo Clinic (Rochester, MN): Philippe R. Bauer; North Shore Medical Center (Salem, MA): Ryan J. Gosselin, Barrett T. Kitch; Albany Medical Center (Albany, NY): Jason E. Cohen, Scott H. Beegle; John H. Stoger Hospital of Cook County (Chicago, IL): Renaud M. Gueret, Aiman Tulaimat; Albany Medical Center (Albany, NY); Shazia Choudry; University of Alabama at Birmingham (UAB) (Birmingham, AL): William Stigler, Hitesh Batra; Duke University Hospital (Durham, NC): Nidhi G. Huff; lowa Methodist Medical Center (Des Moines, IA): Keith D. Lamb, Trevor W. Oetting; Surgical \& Neurosciences Intensive Care Unit of the University of lowa Hospitals and Clinics (lowa City, IA): Nicholas M. Mohr, Claine Judy; Medical Center of Louisiana at New Orleans (New Orleans, LA): Shigeki Saito, Fayez M. Kheir; Tulane University (New Orleans, LA): Fayez Kheir; Critical Care Unit of the University of lowa Hospitals and Clinics (lowa City, IA): Adam B. Schlichting, Angela Delsing; University of California, San Diego Medical Center (San Diego, CA): Daniel R. Crouch, Mary Elmasri; UC San Diego Thornton Hospital (La Jolla, CA): Daniel R. Crouch, Dina Ismail; University Hospital (Cincinnati, OH): Kyle R. Dreyer, Thomas C. Blakeman; University Hospital (Cincinnati, OH): Kyle R. Dreyer, Dina Gomaa; Tower 3B Medical ICU of Brigham and Women's Hospital (Boston, MA): Rebecca M. 
Baron, Carolina Quintana Grijalba; Tower 8C Burn/Trauma ICU of Brigham and Women's Hospital (Boston, MA): Peter C. Hou; Tower 8D Surgical ICU of Brigham and Women's Hospital (Boston, MA): Raghu Seethala; Tower 9C Neurosurgical ICU of Brigham and Women's Hospital (Boston, MA): Imo Aisiku; Tower 9D Neurological ICU of Brigham and Women's Hospital (Boston, MA): Galen Henderson; Tower 11C Thoracic ICU of Brigham and Women's Hospital (Boston, MA): Gyorgy Frendl; Carl J. and Ruth Shapiro Cardiovascular Center, Brigham and Women's Hospital (Boston, MA): Sen-Kuang Hou, Robert L. Owens, Ashley Schomer.

Serbia: Clinical Center of Serbia (Belgrade): Vesna Bumbasirevic, Bojan Jovanovic Military Medical Academy (Belgrade): Maja Surbatovic, Milic Veljovic.

\section{Funding}

This work was funded and supported by the European Society of Intensive Care Medicine (ESICM), Brussels, Belgium, by St Michael's Hospital, Toronto, Canada, and by the University of Milan-Bicocca, Monza, Italy. This work was supported by JSPS KAKENHI JP 16 K15388, Japan.

\section{Availability of data and materials}

Not applicable.

\section{Authors' contributions}

TA conceived of and designed this study, interpreted the data, drafted the manuscript, and revised the manuscript for important intellectual content. FM contributed to the acquisition of data, conducted data cleaning, analyzed the data, interpreted the data, and revised the manuscript for important intellectual content. TP interpreted the data and revised the manuscript for important intellectual content. IN jointly conceived of and designed this study and interpreted the data. UM jointly conceived of and designed this study and interpreted the data. NT jointly conceived of and designed this study and interpreted the data. KK conceived of and designed this study, interpreted the data, and revised the manuscript for important intellectual content. GB interpreted the data and revised the manuscript for important intellectual content. JL conceived of and designed this study, interpreted the data, and revised the manuscript for important intellectual content. All of the authors reviewed, discussed, and approved the final manuscript.

\section{Ethics approval and consent to participate}

All participating ICUs obtained ethics committee approval and obtained either patient consent or ethics committee waiver of consent in the LUNGSAFE study. The study protocol was also reviewed and approved by the ethics committee of Mito Kyodo General Hospital, University of Tsukuba Hospital Mito Medical Center, Japan.

\section{Consent for publication}

Not applicable.

\section{Competing interests}

All authors declare that they have no competing interests.

\section{Publisher's Note}

Springer Nature remains neutral with regard to jurisdictional claims in published maps and institutional affiliations.

\section{Author details}

${ }^{1}$ Department of General Medicine, Juntendo University, 2-1-1, Hongo, Bunkyo-ku, Tokyo 113-0033, Japan. ${ }^{2}$ Department of Health Services Research, University of Tsukuba, Tsukuba, Japan. ${ }^{3}$ Research Center on Public Health, School of Medicine and Surgery, University of Milano-Bicocca, Monza, Italy. ${ }^{4}$ Keenan Research Center for Biomedical Science, Li Ka Shing Knowledge Institute, St. Michael's Hospital, Toronto, Canada. ${ }^{5}$ Interdepartmental Division of Critical Care Medicine, University of Toronto, Toronto, Canada. ${ }^{6}$ Department of Anesthesiology and Intensive Care Medicine, International University of Health and Welfare, School of Medicine, Narita, Japan. ${ }^{7}$ Dipartimento di Medicina e Chirurgia, Università degli Studi Milano Bicocca, Milan, Italy. ${ }^{8}$ Anesthesia, School of Medicine, National University of Ireland, Galway, Ireland.
Received: 8 December 2017 Accepted: 10 July 2018 Published online: 17 August 2018

\section{References}

1. Jaeger JM, Littlewood KA, Durbin CG Jr. The role of tracheostomy in weaning from mechanical ventilation. Respir Care. 2002;47(4):469-80. discussion 481-462

2. Mahmood $\mathrm{K}$, Wahidi MM. The changing role for tracheostomy in patients requiring mechanical ventilation. Clin Chest Med. 2016;37(4):741-51.

3. Hosokawa K, Nishimura M, Egi M, Vincent JL. Timing of tracheotomy in ICU patients: a systematic review of randomized controlled trials. Crit Care. 2015; 19:424.

4. Laffey JG, Bellani G, Pham T, Fan E, Madotto F, Bajwa EK, Brochard L, Clarkson K, Esteban A, Gattinoni L, et al. Potentially modifiable factors contributing to outcome from acute respiratory distress syndrome: the LUNG SAFE study. Intensive Care Med. 2016;42(12):1865-76.

5. Bellani G, Laffey JG, Pham T, Fan E, Brochard L, Esteban A, Gattinoni L, van Haren F, Larsson A, McAuley DF, et al. Epidemiology, patterns of care, and mortality for patients with acute respiratory distress syndrome in intensive care units in 50 countries. JAMA. 2016;315(8):788-800.

6. Groves DS, Durbin CG Jr. Tracheostomy in the critically ill: indications, timing and techniques. Curr Opin Crit Care. 2007:13(1):90-7.

7. Mehta AB, Syeda SN, Bajpayee L, Cooke CR, Walkey AJ, Wiener RS. Trends in tracheostomy for mechanically ventilated patients in the United States, 1993-2012. Am J Respir Crit Care Med. 2015;192(4):446-54.

8. Siempos II, Ntaidou TK, Filippidis FT, Choi AM. Effect of early versus late or no tracheostomy on mortality and pneumonia of critically ill patients receiving mechanical ventilation: a systematic review and meta-analysis. Lancet Respir Med. 2015;3(2):150-8.

9. Andriolo BN, Andriolo RB, Saconato H, Atallah AN, Valente O. Early versus late tracheostomy for critically ill patients. Cochrane Database Syst Rev. 2015;1:CD007271.

10. Laffey JG, Madotto F, Bellani G, Pham T, Fan E, Brochard L, Amin P, Arabi Y, Bajwa EK, Bruhn A, et al. Geo-economic variations in epidemiology, patterns of care, and outcomes in patients with acute respiratory distress syndrome: insights from the LUNG SAFE prospective cohort study. Lancet Respir Med. 2017;5(8):627-38.

11. Young D, Harrison DA, Cuthbertson BH, Rowan K, TracMan C. Effect of early vs late tracheostomy placement on survival in patients receiving mechanical ventilation: the TracMan randomized trial. JAMA. 2013;309(20): 2121-9.

12. Cheung NH, Napolitano LM. Tracheostomy: epidemiology, indications, timing, technique, and outcomes. Respir Care. 2014;59(6):895-915. discussion 916-899

13. Meng L, Wang C, Li J, Zhang J. Early vs late tracheostomy in critically ill patients: a systematic review and meta-analysis. Clin Respir J. 2016;10(6): 684-92.

14. Esteban A, Anzueto A, Alia I, Gordo F, Apezteguia C, Palizas F, Cide D, Goldwaser R, Soto L, Bugedo G, et al. How is mechanical ventilation employed in the intensive care unit? An international utilization review. Am J Respir Crit Care Med. 2000;161(5):1450-8.

15. Durbin CG Jr. Indications for and timing of tracheostomy. Respir Care. 2005; 50(4):483-7.

16. Ortiz JR, Neuzil KM, Shay DK, Rue TC, Neradilek MB, Zhou H, Seymour CW, Hooper LG, Cheng PY, Goss CH, et al. The burden of influenza-associated critical illness hospitalizations. Crit Care Med. 2014;42(11):2325-32.

17. Guerin C, Beuret P, Constantin JM, Bellani G, Garcia-Olivares P, Roca O, Meertens JH, Maia PA, Becher T, Peterson J, et al. A prospective international observational prevalence study on prone positioning of ARDS patients: the APRONET (ARDS prone position network) study. Intensive Care Med. 2018; 44(1):22-37. 